\title{
SNARE-Ware: The Role of SNARE-Domain Proteins in Plant Biology
}

\section{Volker Lipka, ${ }^{1}$ Chian Kwon, ${ }^{2}$ and Ralph Panstruga ${ }^{2}$}

\author{
${ }^{1}$ The Sainsbury Laboratory, John Innes Center, Norwich NR4 7UH, United Kingdom \\ ${ }^{2}$ Max-Planck-Institute for Plant Breeding Research, Department of Plant-Microbe \\ Interactions, D-50829 Köln, Germany; email: panstrug@mpiz-koeln.mpg.de
}

Annu. Rev. Cell Dev. Biol. 2007. 23:147-74

First published online as a Review in Advance on May 21, 2007

The Annual Review of Cell and Developmental Biology is online at http://cellbio.annualreviews.org

This article's doi:

10.1146/annurev.cellbio.23.090506.123529

Copyright (C) 2007 by Annual Reviews. All rights reserved

$1081-0706 / 07 / 1110-0147 \$ 20.00$

\section{Key Words}

cell polarity, exocytosis, endocytosis, secretion, syntaxin, polypeptide and metabolite sorting
Abstract
In yeast and animal cells, members of the superfamily of $\mathrm{N}$ - ethylmaleimide-sensitive factor adaptor protein receptor (SNARE)- domain-containing proteins are key players in vesicle-associated membrane fusion events during transport processes between individ- ual compartments of the endomembrane system, including exocyto- sis and endocytosis. Compared with genomes of other eukaryotes, genomes of monocotyledonous and dicotyledonous plants encode a surprisingly high number of SNARE proteins, suggesting vital roles for this protein class in higher plant species. Although to date it remains elusive whether plant SNARE proteins function like their yeast and animal counterparts, genetic screens have recently begun to unravel the variety of biological tasks in which plant SNAREs are involved. These duties involve fundamental processes such as cytoki- nesis, shoot gravitropism, pathogen defense, symbiosis, and abiotic stress responses, suggesting that SNAREs contribute essentially to many facets of plant biology. 


\section{Contents}

INTRODUCTION............... 148

SNARE PROTEINS .............. 149

PLANT SNARE GENOMICS ...... 151

PLANT Q-SNARES .............. 152

PLANT R-SNARES .............. 153

IN SILICO EXPRESSION AND

SUBCELLULAR

LOCALIZATION ANALYSES

OF ARABIDOPSIS SNARE

GENES AND GENE

PRODUCTS

SNARE REGULATORS AND

SNARE COMPLEX-

ASSOCIATED PROTEINS ...... 154

THE ROLE OF SNARE

PROTEINS IN

CYTOKINESIS ............. 156

THE ROLE OF SNARE

PROTEINS IN

GRAVITROPISM, TISSUE

IDENTITY, AND

AUTOPHAGY

THE ROLE OF SNARE

PROTEINS IN PLANT-

MICROBE INTERACTIONS . . 162

Plant-Pathogen Interactions ...... 162

Plant-Symbiont Interactions ..... 164

THE ROLE OF SNARE

PROTEINS IN ABSCISIC ACID

SIGNALING AND ABIOTIC

STRESS RESPONSES ........ 164

ASSOCIATION OF SNARES

WITH LIPID RAFTS ......... 165

PM: plasma

membrane

SNARE:

$N$-ethylmaleimidesensitive factor adaptor protein receptor sition. The establishment and maintenance of complex eukaryotic compartmentalization require comprehensive transport activities between the various locations within the endomembrane system. Eukaryotes have evolved a sophisticated system to ensure the shipping of cargo within the secretory pathway, a major transport route within the endomembrane system, leading from the endoplasmic reticulum via the Golgi apparatus to the extracellular space (Hanton \& Brandizzi 2006, Sanderfoot \& Raikhel 2003). Small, spherical, membrane-coated transport units called vesicles shuttle and carry loads (e.g., polypeptides and small compounds) between the compartments of the secretory pathway. These include the above-mentioned organelles, the plasma membrane (PM), and the vacuole, another membrane-enclosed organelle. Plant vacuoles are particularly elaborate and can serve diverse purposes, including storage, digestion, and recycling (Bassham \& Raikhel 2000). Unlike in yeast, the presence of a functional vacuole is essential for plant cells (Rojo et al. 2001). In addition to facilitating transport toward the outside of the cell (anterograde transport) and extrusion of cargo (exocytosis), vesicles also contribute to the uptake of loading from the extracellular space (endocytosis) and backward (retrograde) transport processes. Several classes of polypeptides contribute to the targeting and fusion of acceptor and target membranes during these shuttling activities.

In terms of energy, the fusion of a membrane-coated vesicle with a target lipid bilayer is a rather unfavorable process. Eukaryotes have evolved a specialized class of proteins, the soluble $\underline{N}$-ethylmaleimidesensitive factor adaptor protein receptors (SNAREs), that function as mediators of fusion between vesicular and target membranes. These adaptor polypeptides spontaneously form highly stable protein-protein interactions that help to overcome the energy barrier required for membrane fusion. Members of the superfamily of SNARE proteins are found 
in all eukaryotes, including plants. Notably, plants have a somewhat distinct and considerably expanded repertoire of SNAREs compared with that of animals and fungi: In contrast to members of the latter kingdoms, plants lack particular SNARE protein subfamilies but have also evolved few novel types of SNAREs (see below). During the past decade, comprehensive cell biological and biochemical studies as well as both forward and reverse genetic screens have begun to shed light on the roles of SNARE proteins in plant biology. This review focuses on the determined functions of SNAREs in the context of plant biological processes and discusses essential future questions in this research area.

\section{SNARE PROTEINS}

SNARE-domain proteins comprise a superfamily of comparatively small ( 200-400amino-acid) polypeptides that are characterized by the presence of a particular peptide domain, the SNARE motif (Jahn \& Scheller 2006). The SNARE domain is a stretch of 60-70 amino acids consisting of heptad repeats that can form a coiled-coil structure. Via hetero-oligomeric interactions, SNAREs mediate fusion events between membranes in the course of intracellular vesicle-associated traffic and therefore occur on vesicles, organelles of the endomembrane system, and the PM. The association of SNAREs with lipid bilayers is usually conferred by C-terminal transmembrane (TM) domains (Figure 1 $\boldsymbol{a}$ ). Some SNAREs, however, are attached to membranes via lipid anchors. With the exception of SNAP-25-like SNARE proteins, which harbor two SNARE domains separated by a flexible linker, the vast majority of SNAREs possess one SNARE motif (Figure 1a). In addition to the SNARE domain and the Cterminal TM domain, many SNAREs contain $\mathrm{N}$-terminal regulatory sequence motifs that control in vivo SNARE protein activity in concert with a range of accessory polypep- tides (Figure 1 $\boldsymbol{a}$ ). SNAREs mediate membrane fusion by intermolecular interactions among complementary vesicle- and target membrane-associated SNAREs. Upon contact, matching types of SNAREs form a highly stable protein association called the SNARE complex. A typical SNARE complex involves three distinct types of SNARE proteins residing on the target membrane and one SNARE polypeptide located on the vesicle that together contribute to a four-helix bundle of intertwined SNARE domains (for recent reviews, see Brunger 2006, Hong 2005, Jahn \& Scheller 2006). Complex formation is associated with conformational and free-energy changes that are commonly believed to drive the membrane fusion process (Figure $1 \boldsymbol{b}$ ). On the basis of $(a)$ sequence conservation between animal and plant SNAREs, (b) complementation of yeast mutants by plant SNAREs (Bassham \& Raikhel 1998, Bassham et al. 1995, Sato et al. 1997, Tai \& Banfield 2001, Zheng et al. 1999b), (c) accumulating proteinprotein interaction data (Bassham \& Raikhel 1999, Chen et al. 2005, Heese et al. 2001, Rancour et al. 2002, Sanderfoot et al. 2001a, Zheng et al. 2002), and (d) evidence from in vitro liposome fusion studies (Chen et al. 2005), the in planta formation of ternary SNARE complexes and their contribution to membrane fusion events appear very likely. However, direct experimental proof of this is still lacking to date.

SNAREs can be classified either on the basis of their subcellular localization (functional classification) or according to the occurrence of invariant amino acid residues in the center of the SNARE motif (structural classification). Functional classification divides SNAREs into vesicle-associated and target membrane-associated SNAREs ( $v$ - and t-SNAREs, respectively) (Söllner et al. 1993), a categorization that can become problematic in the context of homotypic vesicle fusion events and anterograde trafficking routes. Alternatively, under the structural classification, SNAREs can be grouped as Q- and
Heptad repeats: a structural motif consisting of a repeated seven-amino-acid pattern

Coiled coil: a stable linear protein domain consisting of two or more $\alpha$-helices that are intertwined in a superhelix

TM:

transmembrane

Homotypic vesicle fusion: fusion between identical types of vesicles rather than between a vesicle with a larger organelle 
a

N

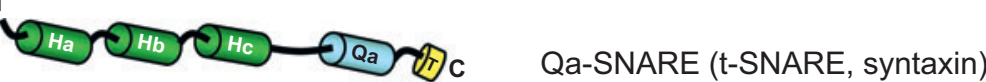

N

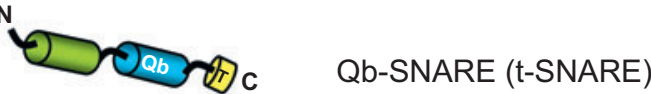

N

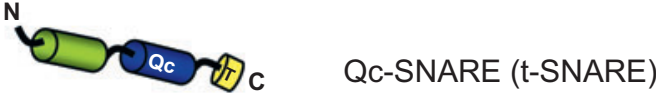

N

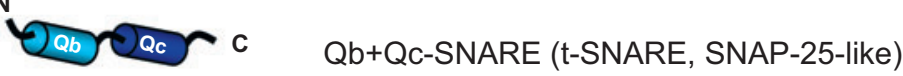

N

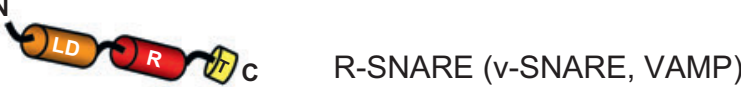

Donor

b compartment

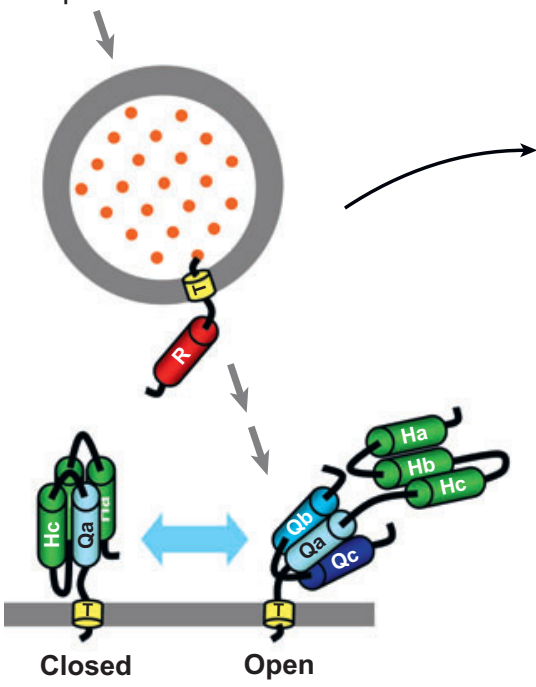

Free SNAREs

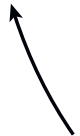

Disassembly and component recycling

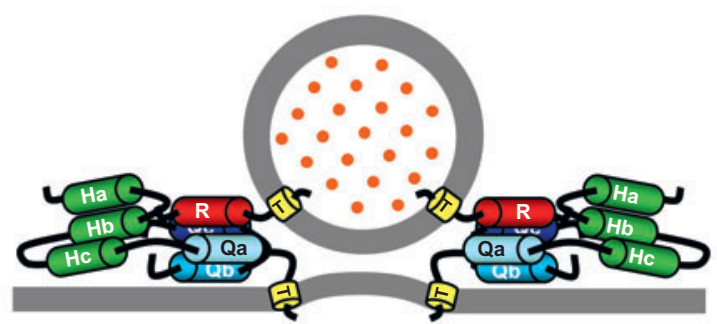

trans complex

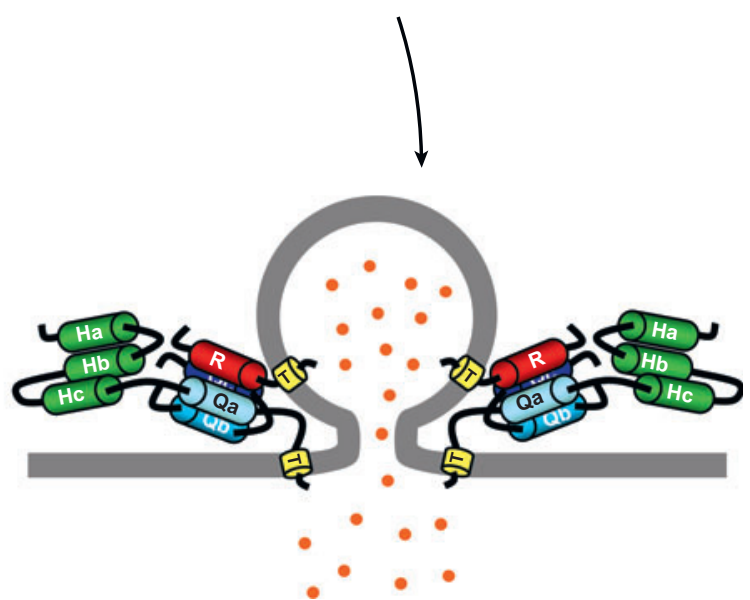

Fusion, cis complex, and cargo release 
R-SNAREs owing to the occurrence of either a conserved glutamine or arginine residue in the center of the SNARE domain (Fasshauer et al. 1998). Generally, t-SNAREs correspond to Q-SNAREs, and v-SNAREs correspond to R-SNAREs. The three types of target membrane-localized Q-SNAREs that contribute to the formation of a SNARE complex can be further subdivided into Qa-, Qb-, and Qc-SNAREs (Bock et al. 2001). SNAP25-like proteins constitute a special case because they comprise a Qb- and a Qc-SNARE motif within a single polypeptide chain, possibly as a result of an ancient gene fusion event. For historical reasons, on the basis of their role in synaptic exocytosis, Qa-SNAREs are also frequently referred to as syntaxins (Bennett et al. 1992). Likewise, vesicleresident R-SNAREs are often designated as VAMPs (vesicle-associated membrane proteins). R-SNAREs can have either a short or long N-terminal regulatory region, further subdividing them into brevins (lat. brevis, short) and longins (lat. longus, long). Again on the basis of their role in synaptic exocytosis, RSNAREs with a short $\mathrm{N}$-terminal domain are also frequently referred to as synaptobrevins (Baumert et al. 1989). In plants, however, this evolutionary young class of R-SNAREs is absent; all known plant R-SNAREs belong to the longin category (Uemura et al. 2005).

\section{PLANT SNARE GENOMICS}

The genomes of all higher plant species investigated so far code for a large repertoire of SNAREs: 60 in the dicotyledonous model species Arabidopsis thaliana (a weed growing in temperate zones) (The Arabidopsis Genome Initiative 2000), 57 in monocotyledonous rice (Oryza sativa, a grass species of subtropical and tropical regions) (International Rice Genome Sequencing Project 2005), and 69 in black cottonwood (Populus trichocarpa, a deciduous dicytyledonous tree endemic to moist woods, ravines, shores, and prairies of western North America) (Tuskan et al. 2006; Table 1). Likewise, comparable numbers of subfamily members are encoded by the various plant genomes (Table 1), suggesting that the enlarged SNARE complement is not related to a particular plant lifestyle and/or biogeographic habitat. Baker's yeast (Saccharomyces cerevisiae) and humans (Homo sapiens) are thought to encode a total of 21-25 and 35-36 members, respectively (Jahn \& Scheller 2006, Sutter et al. 2006a). The higher number of SNAREs in plant species compared with yeast and humans is due predominantly to the enormous expansion of member quantities in conserved SNARE subfamilies and not the evolution of novel SNARE isoforms. In fact, only two subfamilies appear to be plant specific: the NPSN (novel plant-specific SNARE) Qband the SYP7 Qc-SNAREs (Sanderfoot et al.

Figure 1

Domain architecture of major plant SNARE subfamilies and molecular mechanics of SNARE complex formation and vesicle fusion. (a) Scheme of the general domain organization of plant SNARE proteins. Shown are Qa-, Qb-, and Qc-SNARE motifs, the R-SNARE domain (R), regulatory N-terminal regions of Q-SNAREs, the longin domain (LD) of R-SNAREs, and the C-terminal TM helices (T) present in most SNARE proteins. $\mathrm{N}$ and $\mathrm{C}$ denote the $\mathrm{N}$ - and $\mathrm{C}$-terminal ends of the polypeptides, respectively. (b) Scheme of the principle of binary and ternary SNARE complex formation. Vesicle fusion is initiated by regulatory protein-mediated opening of the closed conformation of a target membrane-anchored Qa-SNARE. The resulting exposition of the Qa helix allows association with helices provided by a membrane-associated Qb+Qc-SNARE and an R-SNARE. The latter resides in a vesicle, which buds from a donor compartment after cargo loading and is transported to the acceptor compartment. Association in a trans complex is accompanied by an increase in core $\alpha$-helical structure density that drives transition to the cis complex, membrane fusion, and the release of vesicle cargo into the acceptor compartment. After energy-dependent disassembly and recycling of the individual complex units, the cycle can restart (for more details, see Jahn \& Scheller 2006). For simplicity, the N-terminal longin domain of the R-SNARE is omitted in this scheme. 
Table 1 Number of SNARE type and SNARE subfamily members encoded by the genomes of the dicotyledonous weed Arabidopsis thaliana, the monocot Oryza sativa (rice), and the dicotyledonous tree species Populus trichocarpa (black cottonwood)

\begin{tabular}{|c|c|c|c|c|}
\hline SNARE type & $\begin{array}{c}\text { SNARE } \\
\text { subfamily }\end{array}$ & A. thaliana & O. sativa & P. trichocarpa \\
\hline \multirow[t]{6}{*}{ Qa } & & 18 & 14 & 22 \\
\hline & SYP1 & 9 & 7 & 11 \\
\hline & SYP2 & 3 & 3 & 3 \\
\hline & SYP3 & 2 & 1 & 3 \\
\hline & SYP4 & 3 & 1 & 3 \\
\hline & SYP8 & 1 & 2 & 2 \\
\hline \multirow[t]{6}{*}{$\overline{\mathrm{Qb}}$} & & 12 & 11 & 12 \\
\hline & MEMB & 2 & 1 & 1 \\
\hline & GOS1 & 2 & 3 & 3 \\
\hline & VTI1 & 4 & 3 & 4 \\
\hline & NPSN1 & 3 & 3 & 3 \\
\hline & SEC20 & 1 & 1 & 1 \\
\hline \multirow[t]{7}{*}{$\overline{Q c}$} & & 12 & 16 & 13 \\
\hline & BET1 & 2 & 2 & 3 \\
\hline & SFT1 & 2 & 2 & 1 \\
\hline & USE1 & 2 & 4 & 1 \\
\hline & SYP5 & 2 & 3 & 3 \\
\hline & SYP6 & 1 & 3 & 2 \\
\hline & SYP7 & 3 & 2 & 3 \\
\hline$\overline{\mathrm{Qb}+\mathrm{Qc}}$ & SNAP & 3 & 3 & 4 \\
\hline \multirow[t]{5}{*}{$\mathrm{R}$} & & 15 & 13 & 18 \\
\hline & VAMP71 & 4 & 3 & 5 \\
\hline & VAMP72 & 7 & 5 & 8 \\
\hline & YKT6 & 2 & 2 & 2 \\
\hline & SEC22 & 2 & 3 & 3 \\
\hline
\end{tabular}

2000). The presence of respective genes in the moss Physcomitrella patens and even green algae such as Chlamydomonas reinhardtii suggests that they evolved early in plant evolution. The greater diversification of SNARE isoforms in plants presumably reflects the necessity for some SNAREs to be devoted to plant-specific biological processes such as the plant-specific type of cytokinesis, gravitropic responses, and

Cytokinesis: the division of the cytoplasm to form two separate daughter cells immediately after mitosis the transport of phytohormones [e.g., abscisic acid (ABA) and auxin; see below]. Consistent with the role of SNAREs in other eukaryotes, many of these functions appear to be related to the establishment and/or maintenance of polarity at the (sub)cellular level (Surpin \& Raikhel 2004).

\section{PLANT Q-SNARES}

Plant genomes encode multiple syntaxin-like Qa isoforms belonging to five distinct SYP (syntaxin of plants) subfamilies (Supplemental Figure 1; for all supplemental items follow the Supplemental Material link from the Annual Reviews home page at http://www. annualreviews.org). SYP5, 6, and 7, which were initially grouped as syntaxins, are now regarded as Qc-SNAREs (Pratelli et al. 2004, Sutter et al. 2006a; http://www.cbs.umn. edu/ sande099/atsnare.htm); however, they have retained their original designation. As in yeast and mammals, syntaxins are also the best-studied SNARE proteins in plants. 
The overall structure of the syntaxins consists of an N-terminal autoregulatory domain, a linker, the SNARE domain, and a TM region (Figure 1a). Interestingly, owing to a natural genetic polymorphism, AtSYP23 lacks the C-terminal TM domain in the Arabidopsis reference ecotype Col-0 (Ohtomo et al. 2005, Zheng et al. 1999a). The N-terminal autoinhibitory domain is composed of three helices that are also called the Habc motif. The Habc domain of neuronal syntaxins is folded into three helical bundles that can interact with the SNARE domain, mimicking the parallel four- $\alpha$-helix bundle of the SNARE complex. The intramolecular interaction of the Habc stretch with the SNARE domain, which is also called a closed conformation (Figure 1b), prevents interaction of the syntaxin with other SNAREs (Fernandez et al. 1998, Lerman et al. 2000, Munson et al. 2000). Genetic screens have revealed the contribution of individual syntaxin isoforms to various biological processes such as cytokinesis, pathogen defense, and ABA signaling (see below).

In association with syntaxin-like QaSNAREs, individual Qb- and Qc- (or Qb+Qc-) SNAREs are thought to complement the SNARE complex at the target membrane (Figure 1 $\boldsymbol{b}$ ). Like Qa-SNAREs, Arabidopsis Qb-SNAREs have been implicated in a range of biological processes, including cytokinesis (AtNPSN11), shoot gravitropism (AtVti11), and autophagy (AtVti12) (see below). Remarkably, genetic screens have so far revealed no phenotype for a Qc-SNARE, suggesting at least partial functional redundancy. Qb- and Qc-SNAREs generally also possess an extended $\mathrm{N}$-terminal domain, which, in the case of some animal isoforms, may adopt a coiled-coil structure related to the syntaxin Habc motif (Hong 2005).

Unlike other SNAREs, SNAP-25s contain two SNARE motifs and are classified as a Qb+Qc-SNARE because the N-terminal half is equivalent to Qb-SNAREs and the C-terminal half is similar to Qc-SNAREs (Bock et al. 2001, Fasshauer et al. 1998).
Like their mammalian counterpart, SNAP25, Arabidopsis SNAP-25-like proteins also lack a TM domain. Mammalian SNAP-25 is attached to the PM by palmitoylation of conserved cysteines located in the linker region (Gonzalo et al. 1999, Koticha et al. 1999, Veit et al. 1996). Arabidopsis SNAP-25s, however, have no conserved cysteine(s). Nevertheless, AtSNAP33 localizes to the PM (Heese et al. 2001), suggesting that different posttranslational lipid addition(s) may target it to the PM.

\section{PLANT R-SNARES}

The R-SNAREs encoded by plant genomes can be grouped into three major subfamilies, the VAMPs, YKT6s, and SEC22s (Supplemental Figure 1). Most R-SNAREs are located on trafficking vesicles, anchored by a C-terminal TM domain. A few members, such as AtYKT61 and AtYKT62, are thought to be attached to the vesicular membrane by posttranslational addition of lipid anchors, as in the case of their yeast and mammalian counterparts (McNew et al. 1997). All plant R-SNAREs are so-called longins, comprising an extended $\mathrm{N}$-terminal stretch (the longin domain; see Figure 1a) that, on the basis of data from human R-SNAREs, may be involved in subcellular localization and SNARE complex formation, e.g., by interaction with regulatory polypeptides (MartinezArca et al. 2003, Uemura et al. 2005). Compared with Q-SNAREs, little is known about the biological roles of plant R-SNAREs. AtVAMP711 suppresses Bax-triggered programmed cell death in yeast, suggesting that intracellular vesicle traffic can regulate the execution of apoptosis (Levine et al. 2001). With the exception of a recently discovered salt resistance phenotype (Leshem et al. 2006, see below), no further phenotype has been found in any Arabidopsis RSNARE mutant, suggesting that most RSNAREs act at least partially redundantly, rendering it difficult to infer their function in plants.
Autophagy: a catabolic process to survive extreme environmental conditions; involves the degradation of cellular components in lysosomes 
IN SILICO EXPRESSION AND SUBCELLULAR LOCALIZATION

ANALYSES OF ARABIDOPSIS

SNARE GENES AND GENE PRODUCTS

The availability of comprehensive microarray data (Zimmermann et al. 2004; https://www.genevestigator.ethz.ch) enables a synopsis of the expression profile of SNARE isoforms in various organs, tissue, and cell types of Arabidopsis. Many SNARE genes appear to be expressed in a range of plant tissues. The Qa-SNAREs-in particular SYP22 and SYP32; VTI11 and GOS12 (Qb-SNAREs); BET11, SYP71, SFT11, and USE11 (Qc-SNAREs); SNAP33 (Qb+QcSNARE); and VAMP713, VAMP714, VAMP721, and VAMP722 (R-SNAREs)—all exhibit a ubiquitous expression pattern (Figure 2). Interestingly, many SNAREencoding genes reveal an apparent relative maximum of transcript accumulation in pollen (Figure 2), consistent with the notion that pollen development and function require comprehensive vesicle-associated transport processes, e.g., during the establishment of cell polarity and tip growth of the pollen tube (Hepler et al. 2001).

Recently, Uemura et al. (2004) systematically examined the localization of fluorophore-tagged versions of all Arabidopsis SNARE proteins by transient overexpression in protoplasts. These studies revealed that most SNAREs are associated with specific intracellular compartments, whereas some localize to two or more distinct organelles, possibly owing to shuttling between subcellular compartments. Despite the inherent caveats typically associated with cauliflower mosaic virus $35 \mathrm{~S}$ promoter-driven mis-/overexpression, these and similar experiments by other groups (e.g., Chatre et al. 2005, Latijnhouwers et al. 2005, Takeuchi et al. 2002) suggest at least preferential association of individual SNARE proteins with particular organelles. Likewise, overexpression of full-size SNAREs or cytoplasmic SNARE domains has provided insights into the potential role of these isoforms in subcellular vesicle trafficking (e.g., Chatre et al. 2005, Foresti et al. 2006, Geelen et al. 2002, Sutter et al. 2006b). Together with the above-mentioned gene expression metadata and combined with the results obtained from immunolocalization (e.g., Bassham et al. 2000, Conceicao et al. 1997, Müller et al. 2003, Rancour et al. 2002, Sanderfoot et al. 2001a, Sato et al. 1997) and proteomic studies (e.g., Carter et al. 2004, Marmagne et al. 2004, Mongrand et al. 2004, Morel et al. 2006, Nühse et al. 2003), these experiments provide a preliminary localization and activity atlas for the Arabidopsis SNARE inventory. Supplemental Table 1 summarizes these results.

\section{SNARE REGULATORS AND SNARE COMPLEX-ASSOCIATED PROTEINS}

Although SNARE proteins themselves are able to drive vesicle fusions in vitro, they are not the sole determinants of vesicle fusion and targeting specificity. Beyond in vivo SNARE gene expression, posttranslational modifications, protein turnover and localization patterns, regulatory factors such as

Figure 2

In silico expression analysis of plant SNAREs. The graphic meta-analysis contains microarray-derived expression data of Arabidopsis SNARE protein-encoding genes adapted from the Genevestigator Web site (https://www.genevestigator.ethz.ch). Relative expression levels of the genes in selected tissues/organs are color coded in relation to the tissue/organ with the maximal expression level. For an estimate of absolute expression levels, the respective maximal value (arbitrary microarray value) is indicated for each gene. Data are compiled from independent experiments and sources; absolute values therefore provide only a rough estimate and are not directly comparable. Expression data for SEC222 (At5g52270), BET12 (At4g14455), and VAMP723 (At2g33110) were not available from the Genevestigator Web site. 


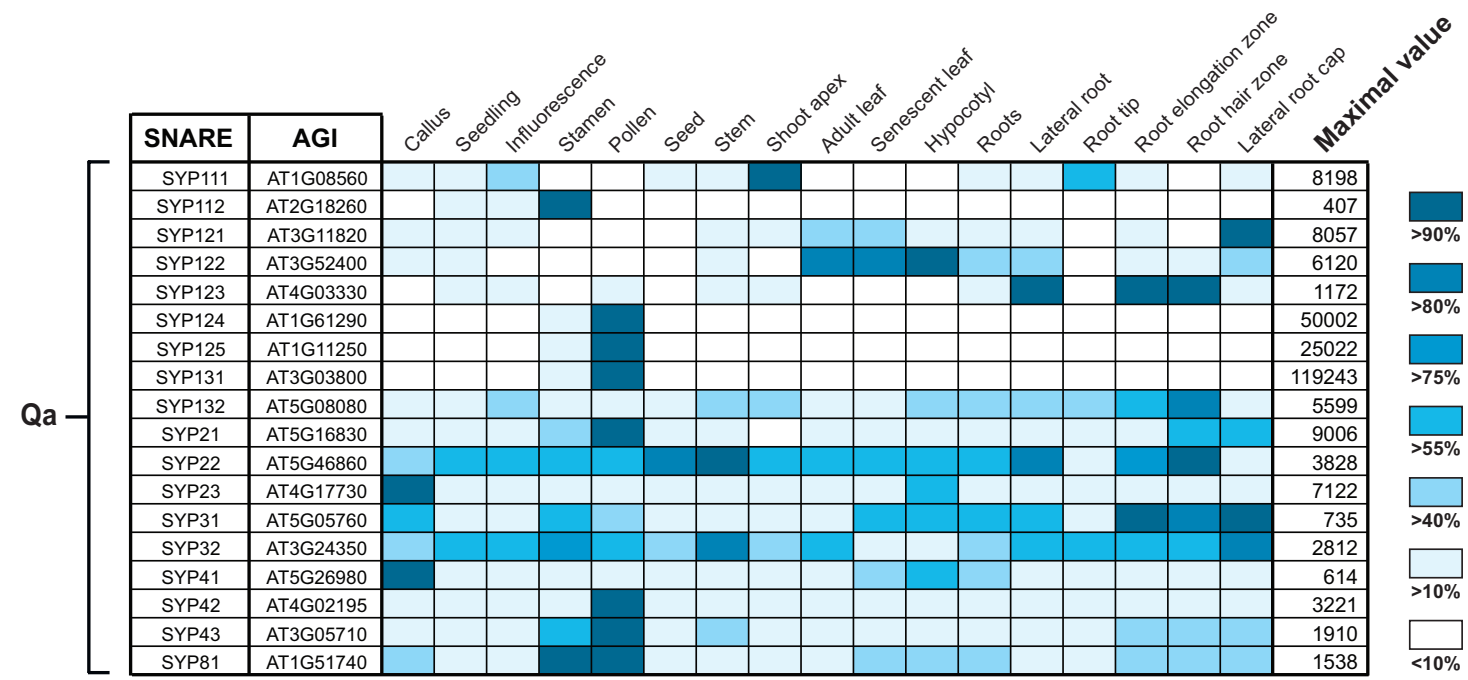

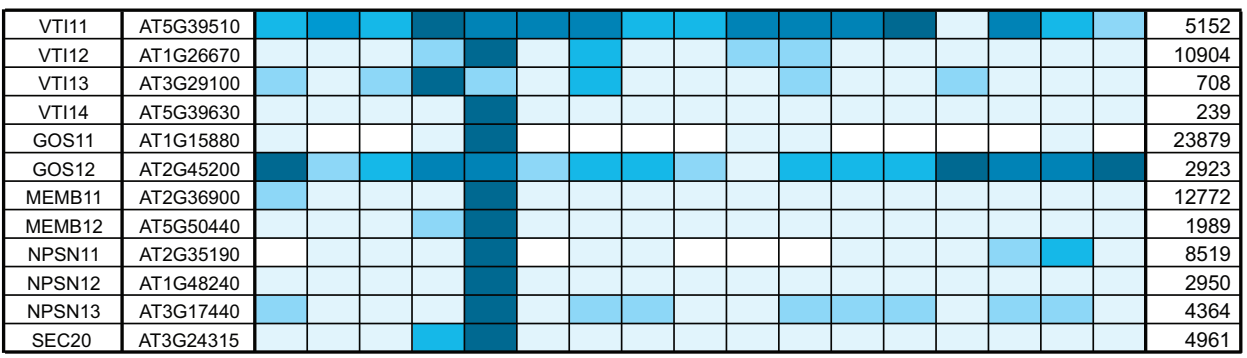

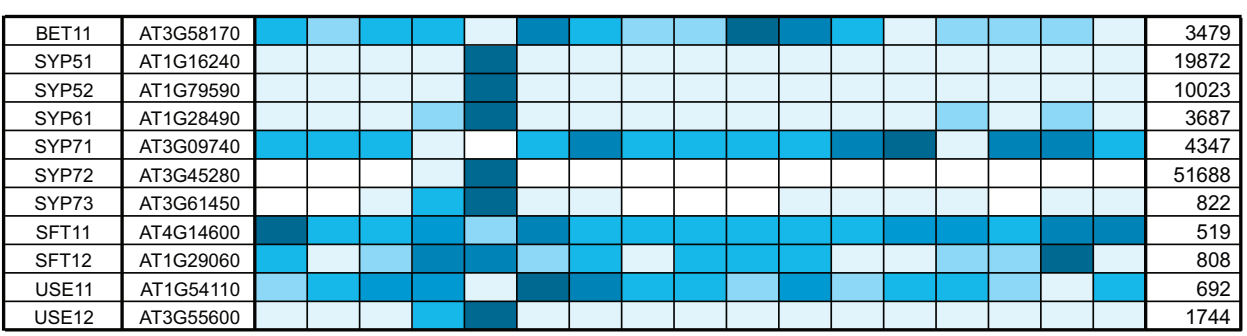

$Q b+Q c-[$

\begin{tabular}{|l|r|l|l|l|l|l|l|l|l|l|l|l|l|l|l|l|l|r|r|}
\hline SNAP29 & AT5G07880 & & & & & & & & & & & & & & & & & & 329 \\
\hline SNAP30 & AT1G13890 & & & & & & & & & & & & & & & & & & 26934 \\
\hline SNAP33 & AT5G61210 & & & & & & & & & & & & & & & & & & 7079 \\
\hline
\end{tabular}

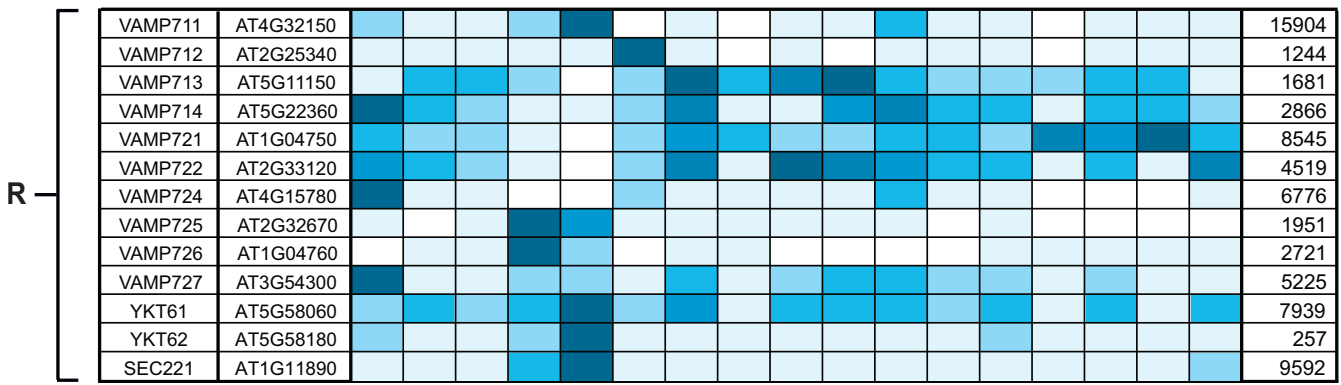


Sec1/Munc18 (SM) proteins are also important (Gerst 2003). SM proteins interact with nonconserved SNARE residues and regulate conformational changes of syntaxins (from closed to open), thereby controlling SNARE complex formation capacity and vesicle fusion (Dulubova et al. 1999, Misura et al. 2000, Yang et al. 2000). The Arabidopsis genome contains six members of the Sec1 family (Sanderfoot \& Raikhel 2003), of which one, KEULE (KEU), has been reported to be involved in cytokinesis (Assaad et al. 2001; see below).

In addition to SM proteins, Ras-related GTPases of the Rab family control multiple steps of eukaryotic vesicle transport such as budding, cargo selection, movement, tethering, and docking (Deneka et al. 2003). Arabidopsis is equipped with 57 potential Rab GTPases that are categorized into eight subfamilies (RabA to RabH) (Sanderfoot \& Raikhel 2003). Although the exact biological functions of most plant Rabs are still elusive, investigators have recently shown that Rha1 and Rab-E1 play crucial roles in vacuolar trafficking and exocytosis, respectively (Sohn et al. 2003, Zheng et al. 2005). In yeast and mammal cells, both Rab and Rho GTPases potentially interact with a multisubunit protein assembly, the so-called exocyst (Sec6/8) complex. This complex may be critical for site specification of vesicle docking and fusion by its actions as a tethering complex before SNAREs and associated proteins mediate the actual fusion event (Elias et al. 2003 and references therein). Bioinformatic analyses of the Arabidopsis genome have identified plant homologs of all known exocyst subunits, suggesting a possibly conserved function in plants (Elias et al. 2003).

Intriguingly, SNARE proteins may finetune membrane fusion specificity by acting in part as inhibitory SNAREs (i-SNAREs) via substituting for or binding to a subunit of a fusogenic SNARE protein to form a nonfusogenic complex (Varlamov et al. 2004). These findings highlight the importance of in vivo SNARE stoichiometry and call for a careful interpretation of transgenic (over)expression data.

To maintain a stable cellular architecture and continuous vesicle trafficking, it is important for eukaryotic cells to recycle proteins and lipids used for vesicle fusion. This recycling process is usually performed by the cooperation of soluble accessory proteins termed $\alpha$-SNAP and NSF (an ATPase). NSF interacts with the SNARE complex via $\alpha$ SNAP and, by ATP hydrolysis, dissociates the complex into compartments (May et al. 2001). Although Arabidopsis has three genes encoding $\alpha$-SNAP and one gene encoding NSF (Sanderfoot et al. 2000), no evidence on the biological role of these genes has been reported.

\section{THE ROLE OF SNARE PROTEINS IN CYTOKINESIS}

Cytokinesis partitions the cytosol and organelles of a dividing cell following separation of the daughter chromosomes (Mayer \& Jürgens 2004, Seguí-Simarro et al. 2004). In somatic plant cells this process is initiated in the center of the division plane by the formation of a transient membrane compartment called the cell plate. Electron microscopic analyses, in vivo imaging, and electron tomographic studies indicate that cell plate formation is the result of Golgi-derived vesicle fusions that give rise to a tubular membrane network at the cell equator (Nebenführ et al. 2000, Samuels et al. 1995, Seguí-Simarro et al. 2004). Recent data suggest that distinct membrane fusion pathways, including endocytotic transport of cell-surface material (Dhonukshe et al. 2006), may also be involved (Rancour et al. 2002).

A genetic screen for Arabidopsis mutants with aberrant seedling body organization allowed the isolation of seedling-lethal knolle (kn) mutants (Lukowitz et al. 1996). $k n$ embryos are characterized by incomplete and disoriented cell divisions resulting in multinucleate and enlarged cells, which defines the mutant as cytokinesis defective and suggests 
an important function for the $\mathrm{KN}$ protein in cell plate formation. Moreover, membrane vesicles accumulate at the plane of cell division but apparently do not fuse normally (Lauber et al. 1997). The mutated gene was identified as the Qa-SNARE AtSYP111 (Lukowitz et al. 1996), which led to the conclusion that $\mathrm{KN}$ may be involved in homotypic fusions of Golgi-derived vesicles. Consistent with a role as a cytokinesis-specific Qa-SNARE, the $K N$ gene is tightly cell-cycle regulated. Its mRNA accumulates transiently in actively dividing tissues of developing flowers and siliques (Lukowitz et al. 1996), and metaanalysis of publicly available microarray data shows high expression levels in the shoot apex and the root tip (Figure 2). Immunofluorescence microscopy revealed that the $\mathrm{KN}$ protein accumulates during $M$ phase, relocates to the cell division plane during telophase, and disappears at the end of cytokinesis (Lauber et al. 1997). Most importantly, Lauber et al. (1997) noticed that $\mathrm{KN}$ is tightly associated with membranes and postulated a specific association with post-Golgi vesicles destined to the cell plate. Recently, however, a series of colocalization experiments showed that $\mathrm{KN}$ is at least partially localized in endosomes (Dhonukshe et al. 2006). Dhonukshe et al. (2006) suggest that both Golgi-derived and endocytotic trafficking pathways are involved in cell plate formation and that $\mathrm{KN}$ may be required for homotypic fusion of endosomes.

Interestingly, ectopic expression of $K N$ by the strong constitutive cauliflower mosaic virus $35 \mathrm{~S}$ promoter leads to PM mislocalization in nonproliferating cells but has no phenotypic effect, whereas comparatively low $35 \mathrm{~S}$ promoter-driven expression in proliferating cells is insufficient to rescue cytokinesisdefective $k n$-mutant embryos (Völker et al. 2001). Thus, high transcription rates during $\mathrm{M}$ phase appear essential for $\mathrm{KN}$ function in cytokinesis. Conversely, $K N$ cis-regulatory sequence-driven expression of Arabidopsis QaSNAREs is not generally sufficient to complement $k n$-mutant cytokinesis defects (Müller et al. 2003). Only one out of three tested Qa-
SNAREs with no cytokinesis-related function, AtSYP112, was targeted to the cell plate and sufficiently related to $\mathrm{KN}$ to perform its function. Intrinsic protein sequence information determining target membrane identity or functional specificity was considered responsible for complementation failure of two other tested Qa-SNAREs, the pathogen defenseassociated and PM-localized AtSYP121 (see below) and the male gametophyte-related and prevacuolar compartment-localized AtSYP21. These intrinsic features may determine interaction capabilities with regulatory proteins and/or cognate SNARE complex partners.

The mutated gene in another cytokinesisdefective Arabidopsis mutant encodes the Sec1 protein KEU (Assaad et al. 2001; Figure $3 a$ ). Sec1 proteins are known regulators of SNARE-mediated vesicle tethering and fusion (see above; Gerst 2003). In vitro protein binding studies and gene interaction analyses suggest that $\mathrm{KN}$ and $\mathrm{KEU}$ interact in vivo to promote vesicle fusion in the cell division plane (Assaad et al. 2001, Waizenegger et al. 2000). Because there are only 6 Sec1 protein family members but 18 Qa-SNAREs encoded by the Arabidopsis genome (see above), it is likely that KEU also regulates other QaSNAREs; that $k e u$, but not $k n$, mutants exhibit aberrant root hair morphogenesis corroborates this idea (Söllner et al. 2002).

The Arabidopsis genome harbors three genes encoding putative $\mathrm{KN} \mathrm{Qb}+\mathrm{Qc}-$ SNARE complex partners, AtSNAP29, 30, and 33 (see above). SNAP30 appears to be expressed exclusively in pollen. In contrast, SNAP29 and 33 are both expressed in a variety of different tissues; the latter has significantly higher expression levels (Figure 2). The derived proteins can all interact with $\mathrm{KN}$ in yeast two-hybrid experiments, suggesting functional redundancy (Heese et al. 2001). In addition to its $\mathrm{KN}$-binding capacity, the ubiquitously expressed SNAP33 is localized predominantly to the PM and colocalizes with $\mathrm{KN}$ at the cell plate of dividing cells (Heese et al. 2001). Consistent with a role in cell plate 
vesicle fusion processes, snap33-knockout mutants show cytokinetic defects such as incomplete cell walls. Remarkably, they also develop aberrant callose deposits and large necrotic lesions on cotyledons and rosette leaves that are reminiscent of pathogen-induced responses
(Figure 3a). Thus, AtSNAP33 appears to be functionally involved not only in cytokinesis but also in other processes (Heese et al. 2001). Indeed, recent findings suggest an interaction of a tobacco homolog of AtSNAP33 with the tobacco Qa-SNARE NtSYP121 (Kargul et al. a
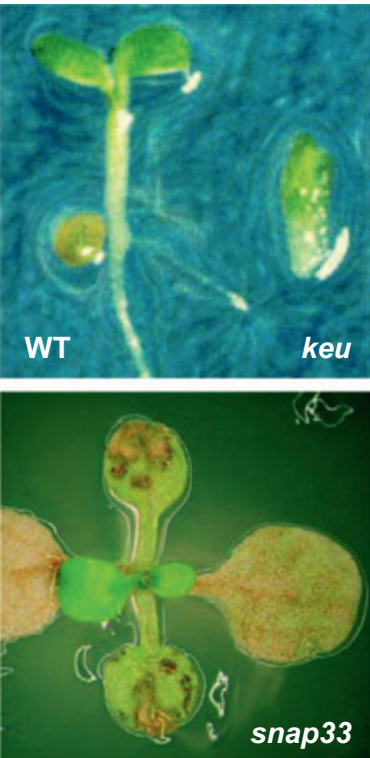

C
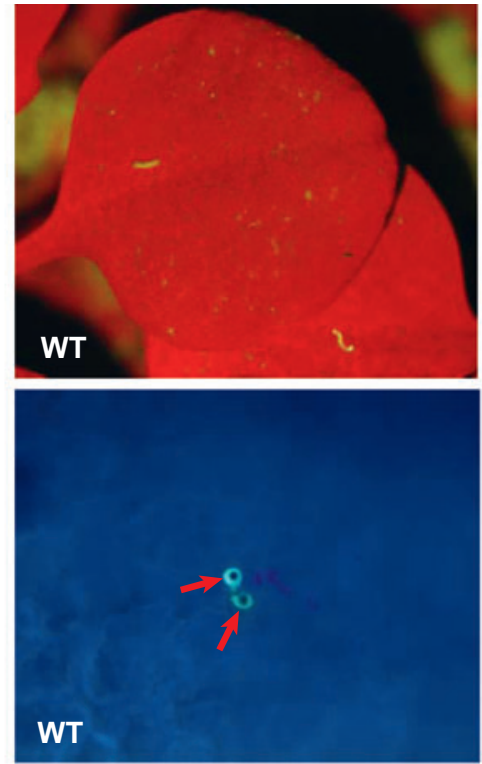
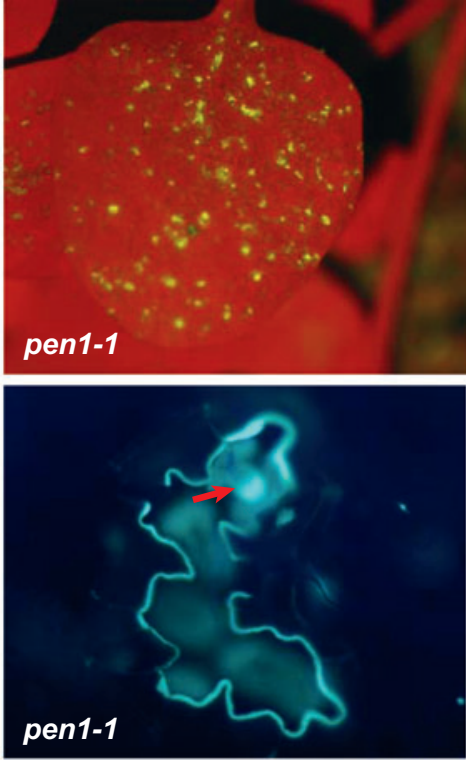

b
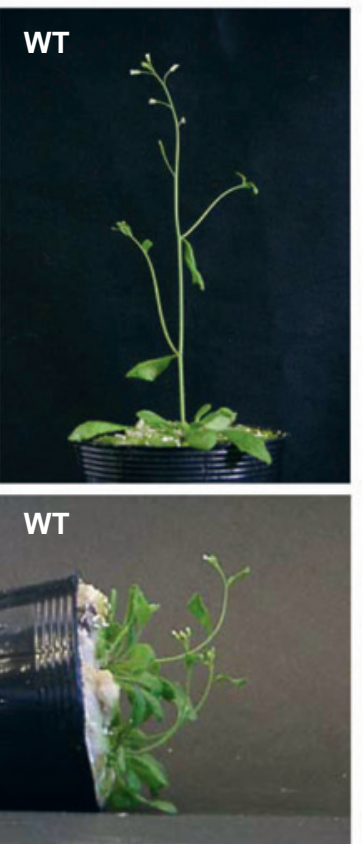
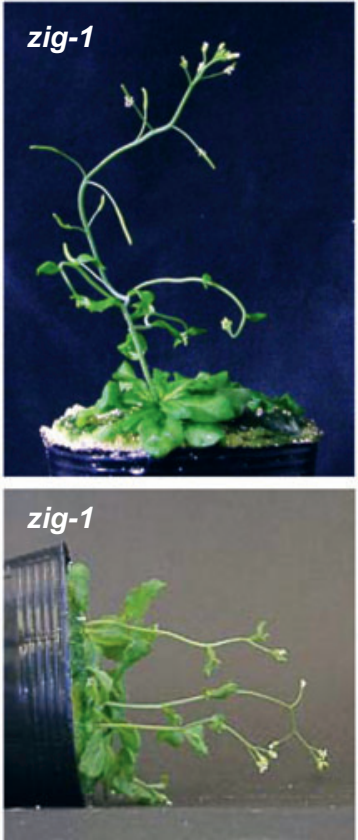

d
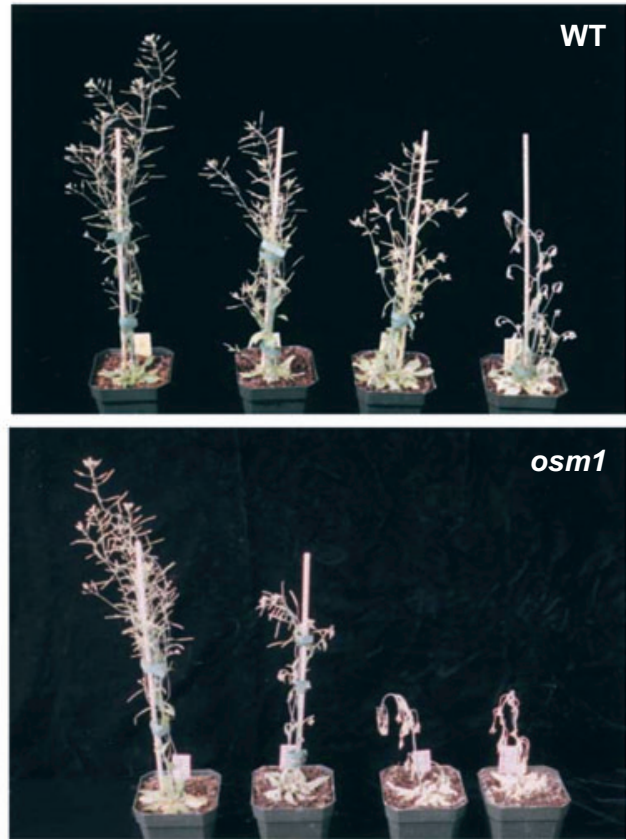
2001) as well as recruitment of AtSNAP33 and its presumptive barley ortholog HvSNAP34 for defense mechanisms executed at the cell periphery (see below).

With KN and SNAP33 as likely partners of a cytokinesis-specific SNARE complex, the only component missing for an authentic SNARE complex until recently was a specific R-SNARE contributing the required fourth helix. That one of the three NPSN genes in the Arabidopsis genome, NPSN11, is highly expressed in actively dividing cells prompted Zheng et al. (2002) to study its gene product in more detail. Immunofluorescence microscopy showed that $\mathrm{KN}$ and NPSN11 colocalize at the cell plate and in punctate subcellular organelles, which do not correspond to Golgi stacks. The latter finding reinforces the notion that non-Golgiderived membrane fusions may contribute to cell plate formation. Coimmunoprecipitation experiments demonstrated that $\mathrm{KN}$ specifically interacts with NPSN11, suggesting that the latter may contribute the fourth helix to a cytokinesis-specific SNARE complex driving homotypic fusions of a membrane compartment that still remains to be unequivocally identified. Intriguingly, however, npsn11-knockout mutants did not show any obvious phenotype, suggesting that other members of the NPSN family can functionally substitute for NPSN11.

Experiments with AtCDC48, an AAA-type ATPase whose yeast and mammal homologs regulate SNARE complex assembly and integrity during cell division, further support the idea that cell plate formation depends on several different membrane fusion pathways that may involve distinct SNARE complexes (Rancour et al. 2002). In Arabidopsis, CDC48 colocalizes at the cell division plane with $\mathrm{KN}$ and another Qa-SNARE, SYP31 (Rancour et al. 2002). In vitro, CDC48 appears to interact specifically in an ATP-dependent manner with SYP31 but not with KN, which assembles into a large $20 \mathrm{~S}$ complex with the adaptor proteins Sec18/NSF and $\alpha$-SNAP. Interestingly, immunolocalization analyses showed that SYP31 is present throughout the cell cycle, associates with both large and small punctate membrane structures of unknown identity during interphase, and marks the division plane during cytokinesis (Rancour et al. 2002). Thus, potentially distinct SNARE complexes seem to mediate a variety of different (homotypic and heterotypic?) subcellular membrane compartment fusions at the forming cell plate during cytokinesis.

Figure 3

Selected phenotypes of Arabidopsis mutants defective in SNARE protein-mediated biological processes.

(a) Seedling phenotypes of five-day-old wild-type (WT) Arabidopsis (upper panel, left);

cytokinesis-defective, dwarfish keu mutant (upper panel, right); and spontaneous brownish lesion development on a snap33-mutant plant (lower panel). Adapted from Heese et al. (2001). Copyright 2001 by The Rockefeller University Press. (b) WT (upper panel, left) and abnormal inflorescence stem morphology of zig-1 mutant (upper panel, right). WT plants (lower panel, left) show a normal gravitropic response after 90 min horizontal gravity stimulation, whereas zig-1 mutants (lower panel, right) show little or no response. Reprinted with permission from Niihama et al. (2005), pp. 555-60. Copyright 2005, Elsevier. (c) Five days postinoculation, low-magnification fluorescence microscopy reveals an enhanced incidence of autofluorescent areas on barley powdery mildew-inoculated pen 1-1-mutant leaves (upper panel, right) when compared with WT (upper panel, left). Fixation of leaf tissue, callose staining, and subsequent fluorescence microscopy at higher magnification demonstrate efficient deposition of callosic plugs at sites of attempted fungal penetration (red arrowheads) on wild-type plants (lower panel, left). In marked contrast, pen 1-1 mutants (lower panel, right) allow fungal invasion (encased and fluorescent fungal feeding structure; red arrowhead), which coincides with local plant-cell-death execution accompanied by whole-cell fluorescence. (d) Phenotypes of one-month-old WT (upper panel) or salt-sensitive osm 1-mutant plants (lower panel) watered with different concentrations of $\mathrm{NaCl}$ (from left to right: $0 \mathrm{mM}$, $200 \mathrm{mM}, 300 \mathrm{mM}, 400 \mathrm{mM}$ ) every three days for three additional weeks. Reproduced with permission from Zhu et al. (2002). Copyright by the American Society of Plant Biologists. 
THE ROLE OF SNARE

PROTEINS IN GRAVITROPISM,

TISSUE IDENTITY, AND

AUTOPHAGY

Most higher plants are sessile organisms that show a bidirectional growth orientation: Shoots grow upward to maximize lightharvesting capabilities, and roots grow downward to anchor the plant in the ground and to ensure sufficient uptake of water and nutrients. The term gravitropism refers to a plant's ability to control organ growth at a specified angle from the gravity vector. The molecular mechanisms that govern gravitropic responses are complex and involve signal perception, transduction, and subsequent adaptive growth adjustments (Blancaflor \& Masson 2003). Changes in sedimentation of starch-filled organelles, called amyloplasts, are believed to constitute one of the initial events in gravity perception (Sack 1991). In shoots these specialized organelles occur in the endodermis (statocytes), and in roots they occur in the columella cells of the root cap (statocytes). Ultimately, signal transduction cascades that mediate the relocalization of auxin transporters and thus alter auxin flux cause compensatory asymmetric growth responses.

Several agravitropic mutants that are affected in various aspects of this complex process have been isolated (Masson et al. 2002). These include Arabidopsis plants with mutations in two different SNARE-encoding genes. In the corresponding mutants, sgr3 and $\operatorname{sgr} 4$ (the latter is also known as zig or zigzag) (Figure $3 \boldsymbol{b}$ ), shoot endodermal statocytes do not sediment according to the gravity vector, whereas root cap statocytes behave normally (Kato et al. 2002, Morita et al. 2002, Saito et al. 2005, Yano et al. 2003). Consistent with these results, both mutants show abnormal inflorescence stem gravitropic responses (Figure $3 \boldsymbol{b}$ ). Interestingly, however, hypocotyl gravitropism is abnormal in sgr4, but not in sgr3, mutants, documenting tissue-specific differences (Fukaki et al. 1996, Yamauchi et al. 1997). Pro- nounced morphological defects such as zigzag growth of the inflorescence stem, small size, and wrinkled leaves are additional phenotypic characteristics of $\operatorname{sgr} 4$ mutants, whereas $\operatorname{sgr} 3$ 1 -mutant plants exhibit no general growth defects (Yano et al. 2003). SGR3 encodes the QaSNARE AtVAM3/SYP22 (Yano et al. 2003), and ZIG/SGR4 codes for the Qb-SNARE AtVTI11 (Kato et al. 2002). Of the three described sgr4 mutant alleles, one (zig-2) completely lacks the coding region for AtVAM3, whereas $z i g-3$, whose gravitropic response is the most weakly affected, shows a substitution in a conserved amino acid of the coiledcoil domain (Kato et al. 2002). In the original sgr3-1 mutant, a single amino acid substitution adjacent to the SNARE motif appears to reduce the protein's affinity for putative gravitropism-specific SNARE complex partners (Yano et al. 2003). However, this particular mutation may not be deleterious enough to cause other morphological phenotypes. Indeed, a novel semidwarf mutant with reduced elongation of inflorescence stems and leaves has been recently identified. This mutant harbors a 34-bp deletion in the sixth intron of AtVAM3/SYP22, probably preventing proper mRNA splicing and protein synthesis (Ohtomo et al. 2005). Remarkably, this mutant also exhibits abnormal development of idioblasts, specialized leaf cells accumulating thioglucoside glucohydrolases (myrosinases) that are involved in the release of toxic compounds to repel phytophagous insects or phytopathogenic microorganisms (Ueda et al. 2006). These findings reinforce the notion that AtVAM3/SYP22 is required for various aspects of plant development.

Both AtVTI11 and AtVAM3/SYP22 are localized to prevacuolar or vacuolar compartments (Sato et al. 1997, Zheng et al. 1999b), and together with SYP51 they may form a SNARE complex that contributes to vesicular trafficking to these organelles (Sanderfoot et al. 2001a, Yano et al. 2003). On the subcellular level, sgr 3 and sgr4 mutants have abnormally structured vacuoles that do not flexibly surround the statocysts, as do wild-type plants 
(Morita et al. 2002, Yano et al. 2003). Therefore, the mutations may affect proper vacuole biogenesis, which may in turn mechanically constrain the movement of amyloplasts and thus affect gravitropism. Alternatively, owing to inefficient transport or missorting as a consequence of mutations in AtVTI11 or AtVAM3/SYP22, lack of regulatory proteins like mechanosensitive ion channels or proton pumps in vacuole membranes may impair the signal transduction cascades required to execute gravitropic responses.

Interestingly, endodermis-specific expression of both AtVTI11 and AtVAM3/SYP22 complements gravitropic defects in the corresponding mutants, whereas additional sgr4specific defects such as zigzag stems and malformed leaf morphology are retained (Morita et al. 2002). This suggests important tissuespecific roles for the v-SNARE VTI11 in biological processes other than gravitropism. In Arabidopsis, the VTI1 family is composed of four closely related members, VTI11, 12, 13 , and 14 , the first two of which are expressed at reasonable levels in a variety of organs and tissues (Figure 2; Surpin et al. 2003). VTI12 forms SNARE complexes at the trans-Golgi network with the Sec1 family protein VPS45 and members of the SYP4 and SYP6 t-SNARE families (Bassham et al. 2000, Sanderfoot et al. 2001a), reflecting marked differences with VTI11 with respect to localization and putative SNARE complex partners. Recent analyses suggest, however, that the gene products of VTI11 and VTI12 are at least partially functionally redundant. Surpin et al. (2003) found that homozygous double mutants are embryo lethal, suggesting vital functional overlap between the two genes. Moreover, vti11/vti11 VTI12/vti12 plants exhibit an enhanced zigzag stem morphology when compared with vti11 (sgr4) single mutants, suggesting that VTI12 can at least partially substitute for VTI11. Plants with an enhanced zig phenotype are characterized by a loss of discernible tissue types. This demonstrates a significant role for VTI11 in the establishment and maintenance of tissue orga- nization and identity in addition to its role in plant gravitropism. Conversely, VTI11/vti11 vti12/vti12-mutant plants are indistinguishable from their vti12 parents and exhibit no abnormal developmental phenotype under normal growth conditions. However, under nutrient-poor conditions and in assays with detached leaves, vti12 mutants exhibit accelerated senescence phenotypes similar to previously characterized Arabidopsis autophagy mutants (Surpin et al. 2003). This suggests that, analogous to yeast autophagy, VTI12 may be involved in autophagosome traffic to the vacuole, where cytosolic contents or organelles are degraded and reallocated for essential processes.

A recent screen for suppressors of the $z i g 1$ (vti11; sgr4-1) mutation yielded one dominant mutant, zip1 (zig suppressor 1), which fully restored wild-type morphology and gravitropism (Niihama et al. 2005; Figure 3b). A map-based cloning strategy revealed a point mutation in the closest homolog of VTI11, $V T I 12$, which at the protein level converts a glutamate to a lysine. Surprisingly, this particular amino acid exchange appears to convert both SNARE complex formation specificity and subcellular localization, allowing ZIP1 to function as VTI11.

In summary, plant SNAREs appear to play essential roles in plant development, a statement already expressed by Sanderfoot et al. (2001b), who found that disruption of individual members of the SYP2 and SYP4 families is embryonic lethal. However, growing evidence suggests the potential for at least partial functional redundancy, whereas the above-mentioned ZIP1/VTI11 example of specificity conversion (Niihama et al. 2005) demonstrates how easily subtle mutations can affect functional specialization. Evolutionary selection for such modifications may have had (and possibly still has) a significant impact on functional diversification, resulting in the recruitment of SNARE variants for different biological processes. Notably, QaSNAREs SYP121 and 122 are closely related to the cytokinesis-specific Qa-SNARE 
Symbiosis: the relation between two different species of organisms (e.g., plant and microbe) that are interdependent; each gains benefits from the other

Paramural bodies: membranous vesicle-like structures located between the cell wall and the plasma membrane

Multivesicular bodies: lipid-bilayer-covered vesicle-like cytoplasmic structures that contain a number of small vesicles
SYP111 (the above-mentioned KN; Supplemental Figure 1). Both SYP121 and SYP122 are involved in plant defense (see below). Interestingly, single-knockout mutations do not show any obvious developmental phenotypes. Double mutants, however, exhibit a severely stunted and necrotic growth phenotype, demonstrating functional redundancy between them during development (Assaad et al. 2004). These findings also suggest a functional recruitment shift of the latter two SNARE proteins for plant-pathogen interaction-triggered secretory processes; potentially evolutionarily older developmental functions might still be immanent but no longer at the fore.

\section{THE ROLE OF SNARE PROTEINS IN PLANT-MICROBE INTERACTIONS}

Interactions between plants and microbes can be broadly grouped into two categories. On the one hand, there are encounters with potentially pathogenic microorganisms that may ultimately result in disease. On the other hand, most plants have also coevolved a mutually beneficial coexistence with some bacterial and fungal species, a condition that is referred to as symbiosis. There is accumulating evidence that plant endo- and exocytotic processes play crucial roles in the course of both types of plant-microbe interactions. Along these lines, recent reports indicate that SNAREs represent key factors of plant defense and that the expression of some isoforms is tightly associated with the establishment of symbiotic relationships. Functions of SNARE proteins in plant-microbe interactions may relate to the uptake of microbial effector molecules, to vesicle-associated defense responses, and to the accommodation of microbial infection structures.

\section{Plant-Pathogen Interactions}

Researchers have thought for a long time that secretory processes are likely to con- tribute to defense responses in plant-microbe interactions. For example, site-specific, localized accumulation of antimicrobial secondary metabolites (so-called phytoalexins) was observed in the apoplast of Sorgbum bicolor cells attacked by the fungal pathogen Colletotrichum graminicola (Snyder \& Nicholson 1990). In this study, the deposition of the phytoalexin initiated with the occurrence of spherical cytoplasmic inclusions of approximately $1 \mu \mathrm{m}$ diameter that subsequently coalesced to larger entities of $\sim 20 \mu \mathrm{m}$ diameter. Likewise, in barley powdery mildew interactions, the accumulation of $\mathrm{H}_{2} \mathrm{O}_{2}$-containing vesicular structures of 2-3 $\mu \mathrm{m}$ diameter has been reported (Collins et al. 2003, Hückelhoven et al. 1999). Ultrastructural analysis revealed that these vesicle-like bodies consist of a range of cellular structures, including miniature cell wall appositions, paramural bodies, and multivesicular bodies. This situation possibly reflects the specialized transport of different antimicrobial proteins, regulatory polypeptides, cell wall components, and other defense-related cargo (An et al. 2006). Besides the extrusion of phytoalexins, the exocytosis of a bouquet of defense-associated polypeptides, socalled pathogenesis-related proteins, into the apoplastic space is a common response to microbial attack that has been observed in numerous pathosystems (for example, see Carr et al. 1987).

Despite the longstanding, wellacknowledged role of secreted antimicrobial compounds and polypeptides at the cell periphery, transport routes from the site of synthesis to the site of action have remained largely unknown. Recently, Collins et al. (2003) demonstrated a fundamental role for a SNARE-domain protein in plant defense. Loss-of-function alleles of AtSYP121 (PEN1; encoding a Qa-SNARE) and its barley ortholog, HvROR2, enable elevated levels of host cell entry either by nonadapted fungal species (on Arabidopsis; Figure 3c) or in highly resistant barley mlo mutant alleles. Lack of AtSYP121 results in a delay in the formation of localized cell wall appositions (so-called 
papillae) at attack sites of nonadapted powdery mildews, suggesting that AtSYP121 contributes to the timely establishment of pathogen-triggered cell wall reinforcements (Assaad et al. 2004). Recent findings, however, indicate that the roles of AtSYP121 and the closely-sequence-related AtSYP122 extend beyond limiting fungal penetration and possibly also include the regulation of postinvasive defense layers (Zhang et al. 2007). Genetic studies involving triple mutants defective in AtSYP121 and AtSYP122 and the salicylic acid signaling pathway revealed that the two t-SNAREs may represent negative regulators of salicylic acid-, jasmonic acid-, and ethylene-dependent defense pathways (Zhang et al. 2007).

Silencing of the barley Qa+Qb-SNAREencoding gene $H v S N A P 34$, the ortholog of AtSNAP33, revealed increased fungal entry rates in the otherwise fully resistant $m l o$ genotype, similar to the loss of HvROR2 QaSNARE function (Collins et al. 2003). In addition to mlo-mediated resistance, HvSNAP34 appears to be required for nonhost immunity and basal defense but not for isolate-specific resistance (Douchkov et al. 2005). In yeast two-hybrid assays, HvSNAP34 interacted with the PM-resident HvROR2 syntaxin, suggesting that HvROR2 and HvSNAP34 may represent cognate SNARE partners that form binary SNARE complexes in planta. Taken together, these results suggest an essential and evolutionary conserved role for a PM-localized SNARE complex during defense against fungal pathogens (Collins et al. 2003, Schulze-Lefert 2004). On the basis of the pathogen-responsive gene expression (Wick et al. 2003), a contribution of the Arabidopsis ortholog AtSNAP33 in plant defense also appears likely. Early seedling lethality of the respective Atsnap33-knockout mutant (Figure 3a) unfortunately has precluded experimental assessment of this prediction.

Following challenge by powdery mildew fungi, fluorophore-tagged variants of barley and Arabidopsis syntaxins HvROR2 and AtSYP121 became concentrated at attempted fungal entry sites (Assaad et al. 2004, Bhat et al. 2005). In addition to the HvROR2 syntaxin, a subset of further PM-resident barley proteins also accumulates at locations of fungal challenge (Bhat et al. 2005, Eichmann et al. 2006), suggesting the formation of a pathogen-triggered PM microdomain. Intriguingly, focal accumulation of fluorophoretagged AtSYP121 syntaxin was not seen beneath attempted entry sites of adapted or nonadapted Colletotrichum species, fungal pathogens that cause the widespread anthracnose disease (Shimada et al. 2006). However, as in the case of nonadapted powdery mildew species (Assaad et al. 2004), Atsyp121 mutants exhibited a delay in the deposition of callose in papillae, reinforcing the notion that AtSYP121 function is associated with the timely formation of cell wall appositions in response to attack by various fungal pathogen species. Interestingly, despite delayed papilla formation there was no increase in the entry rate of nonadapted anthracnose fungi, suggesting that other defense reactions suffice to prevent ingress by these fungal pathogens. These assumed defense reactions possibly involve distinct vesicle populations tagged with R-SNAREs that interact with cognate QaSNAREs other than AtSYP121.

In a proteomic study aimed at identifying PM-resident polypeptides that become phosphorylated upon treatment with the general bacterial elicitor flg22, Nühse et al. (2003) discovered that the syntaxin AtSYP122, a close relative of the above-mentioned AtSYP121, is rapidly phosphorylated. In vitro phosphorylation of AtSYP122 occurs at two serine residues at the $\mathrm{N}$ terminus of the protein in a calcium-dependent manner, providing a potential link between defense-associated calcium signaling and protein phosphorylation. Likewise, Heese et al. (2005) have reported rapid phosphorylation of a tobacco syntaxin upon triggering a race-specific resistance response. These findings suggest that the phosphorylation of Qa-SNAREs may be a conserved early response in various types of plant defense. 
Although most of the above-mentioned findings corroborate a role for SNARE proteins in defense-related exocytosis, a recent report also highlights the crucial role of host endocytosis in plant-microbe interactions. The Arabidopsis PM-resident receptor kinase FLS2 serves as a pattern recognition receptor for flagellin, the main building subunit of the bacterial motility organ (reviewed in Gómez-Gómez \& Boller 2002). Flagellin represents a widespread pathogen-associated molecular pattern (PAMP), and its perception triggers innate immune responses that ultimately restrict bacterial invasion (Zipfel et al. 2004). Work by Robatzek et al. (2006) now shows that a functional GFP-FLS2 fusion protein is internalized into intracellular mobile vesicles upon activation by the flagellin epitope flg22. It is, however, currently unclear whether this ligand-triggered receptor endocytosis plays a role in receptor desensitization and/or defense signaling.

Finally, in the context of plant-pathogen interactions, it is not only defense reactions on the host side for which SNARE proteins are crucial. A recent study provides evidence that the t-SNARE Yup1 is essential for endocytosis during the initial steps of development of the plant-pathogenic corn smut fungus $U_{s t i-}$ lago maydis, highlighting the importance of SNAREs for both partners of plant-microbe interactions (Fuchs et al. 2006).

\section{Plant-Symbiont Interactions}

In comparison with the continuously growing knowledge about the function of SNARE proteins in the context of pathogen defense, little is known about the role of these polypeptides in symbiotic relationships. In the legume species Lotus japonicus, one of two LjSYP32 isogenes (LjSYP32-1) encoding orthologs of the AtSYP32 syntaxin appears to function in the development of root nodules, specialized organelle-like structures that form the interaction zone between symbiotic bacteria (rhizobia) and the plant's root tissue (Mai et al. 2006). Like AtSYP32 (Figure 2),
LjSYP32-1 is ubiquitously expressed, with a preference for roots. Transgenic Lotus lines expressing LjSYP32-1 antisense constructs showed a general growth defect and exhibited smaller roots and in part irregularly shaped nodules, suggesting that LjSYP32-1 plays a role in plant development and root nodule organogenesis (Mai et al. 2006). Reminiscent of Atsyp121/Atsyp122 double-mutant studies (Assaad et al. 2004), these findings in Lotus reinforce the notion that particular SNAREs have at least dual roles in developmental programs and interactions with microorganisms (Lipka \& Panstruga 2005; see above). Similar to LjSYP32-1, in Medicago truncatula, MtSYP132, the ortholog of AtSYP132, was localized to root nodules (Catalano et al. 2004, 2007). Western blot analysis and immunolocalization revealed the presence of MtSYP132 in the specialized symbiosome membranes of so-called infection threads and infection droplets (Catalano et al. 2007). Taken together, these studies provide the first evidence for a role for plant SNARE isoforms in the establishment of plant-symbiont interactions, possibly by their contributions to the delivery of specialized cargo toward the symbiosome membrane. However, unequivocal genetic evidence for a function for any SNARE proteinencoding gene during symbiosis is still lacking. Pleiotropic effects (Mai et al. 2006) or even lethality associated with respective lossof-function mutants may be preventing the identification of plant SNARE mutants in forward genetic screens for symbiosis-deficient mutants (Mao et al. 2005; NodMut database, http://nodmutdb.vbi.vt.edu/).

\section{THE ROLE OF SNARE PROTEINS IN ABSCISIC ACID SIGNALING AND ABIOTIC STRESS RESPONSES}

Along with biotic stresses, plants also have to cope with a range of abiotic stresses, e.g., drought, heat, cold, and salinity. Stomatal closure is a common response in reply to various abiotic stress cues, including 
heat, drought, and salinity. The phytohormone ABA is thought to play a pivotal role in the regulation of cellular responses upon abiotic stresses. A cDNA screen in frog (Xenopous laevis) oocytes led to the identification of a tobacco syntaxin, NtSYR1 (the ortholog of Arabidopsis AtSYP121/AtSYP122), which interferes with ABA-triggered potassium and chloride ion fluxes in both Xenopous oocytes and Nictotiana tabacum guard cell protoplasts (Leyman et al. 1999). Likewise, transient expression of a truncated version of NtSYR1, expected to exert a dominant negative effect, led to a complete loss of ABA-induced changes in ion fluxes. Because some mammalian syntaxin isoforms physically associate with ion channels (Naren et al. 1997), these findings have been interpreted as evidence for a potential additional role for syntaxins in the regulation of plant ion channel activities (Pratelli et al. 2004, Sutter et al. 2006a). NtSYR1 appears to interact with a tobacco homolog of the Qb+Qc-SNARE AtSNAP33 (Kargul et al. 2001). Consistent with a potential role in abiotic stress responses, NtSYR1 expression is responsive to ABA, salt stress, and wounding in the leaves but not roots of tobacco (Leyman et al. 2000). Recent data, however, revealed that the truncated dominant-negatively-acting variant of the AtSYP121 syntaxin contributes to the proper trafficking and localization of the KAT1 potassium channel rather than to the regulation of its activity (Sutter et al. 2006b). This suggests that the observed differential ion channel responses may be related to altered channel turnover upon syntaxin misexpression.

In a genetic screen for altered salt tolerance in Arabidopsis, a knockout line [osm1 (osmotic stress-sensitive mutant 1)] of the gene encoding the AtSYP61 syntaxin was identified in a population of T-DNA-tagged mutants (Zhu et al. 2002). The mutant exhibited increased sensitivity to both ionic and nonionic osmotic stresses in a root bending assay. Additionally, the knockout line was hypersensitive to drought stress (Figure $3 d$ ), and its stomata were insensitive to ABA-induced closing and inhibition of opening. Surprisingly, transgenic Arabidopsis lines expressing an AtVAMP711 antisense fragment as well as individual AtVAMP711, AtVAMP713, or AtVAMP714T-DNA insertion lines exhibited the opposite phenotype, namely improved salt tolerance (Leshem et al. 2006). This phenotype coincided with a failure of osmotic stressinduced, reactive oxygen species-containing endosomal vesicles to fuse with the central vacuole. Collectively, these data suggest antagonistic functions for individual SNAREs in abiotic stress responses.

\section{ASSOCIATION OF SNARES WITH LIPID RAFTS}

Lipid rafts represent cholesterol- and sphingolipid-enriched PM microdomains that can selectively include or exclude proteins and that supposedly serve as cellular signaling platforms (Pike 2006). Individual rafts are thought to be small (10-200 nm) but able to coalesce into larger entities in a stimulus-dependent manner (Pike 2006). In various types of animal cells, several syntaxins have been reported to reside in lipid raft-like PM microdomains (e.g., Chamberlain et al. 2001, Lang et al. 2001; reviewed in Salaün et al. 2004). There is increasing evidence for the existence of lipid rafts in plants (Mongrand et al. 2004; reviewed in Bhat \& Panstruga 2005), and proteomic studies in tobacco recently revealed the potential presence of several syntaxin isoforms in $\mathrm{PM}$ microdomains (Mongrand et al. 2004, Morel et al. 2006). Reminiscent of the reported stimulus-triggered clustering of lipid rafts, fluorophore-tagged Arabidopsis and barley syntaxins AtSYP121 and HvROR2 exhibit focal accumulation beneath attempted fungal attack sites (Assaad et al. 2004, Bhat et al. 2005). Moreover, staining with the sterol-specific dye filipin revealed the local accumulation of sterols around sites of fungal challenge (Bhat et al. 2005). Studies in our laboratory have indeed confirmed 
a partial sterol-dependent association of the cellular AtSYP121 syntaxin pool with detergent-resistant membranes, a characteristic feature of raft-associated proteins (N. Zappel \& R. Panstruga, unpublished data). Taken together, the findings in plants seem to corroborate the data obtained in animal cells, pointing toward a concentration of certain SNAREs in PM microdomains, possibly to govern (polarized) sites of exocytosis temporally and spatially (Salaün et al. 2004). Recent experiments employing a fluorophore-tagged variant of the tobacco KAT1 potassium channel and dominantly acting NtSYR1 syntaxin fragments revealed a potential role for SNARE proteins in the traffic and distribution of KAT1 in distinct PM microdomains (Sutter et al. 2006b). These findings suggest that syntaxins may not only reside in lipid rafts but also, at least in part, contribute to the establishment of these PM microdomains.

\section{SUMMARY POINTS}

1. All studied higher plant genomes encode a similar comprehensive set of SNAREs, including two plant-specific Qb subfamilies (NPSN and SYP7).

2. Many plant SNARE genes exhibit tissue-specific expression patterns as well as a distinct subcellular localization of the respective gene products.

3. Plant SNAREs contribute to essential developmental processes (cytokinesis, autophagy, idioblast morphogenesis) and physiological responses (gravitropism, abiotic stress, pathogen defense, symbiosis), many of which at the (sub)cellular level involve the establishment and/or maintenance of polarity.

4. Some SNAREs appear to fulfill dual roles in development as well as in physiological response pathways.

5. Like their animal counterparts, some SNARE isoforms seem to be associated with lipid raft-like plasma membrane microdomains.

\section{FUTURE ISSUES}

1. The capability of plant SNAREs to form ternary SNARE complexes and their actual contribution to in planta vesicle trafficking should be verified.

2. The full set of biologically meaningful binary and ternary SNARE complexes occurring in plants needs to be established.

3. Methods for the isolation of vesicle subpopulations to determine the cargo transported by individual vesicle types characterized by the presence of distinct SNARE isoforms need development.

4. The (plant-specific) regulatory proteins of binary/ternary SNARE complex assembly/ disassembly should be uncovered.

5. Future research should determine whether the dual function of some SNARE proteins in development and physiological responses is due to $(a)$ changes in expression pattern and/or subcellular localization, $(b)$ the presence/absence of particular regulatory proteins, or $(c)$ changes in vesicle cargo. 
6. Whether the localization of particular SNAREs in lipid raft-like plasma membrane microdomains is related to the sites of exocytosis/endocytosis needs resolution.

7. Potential functions of SNAREs distinct from vesicle trafficking (e.g., regulation of ion channels?) should be clarified.

8. Whether-and if so, which-SNAREs contribute to further plant-specific and cell polarity-related biological processes such as pollen tube expansion, root hair growth, and trichome development needs to be unraveled.

\section{DISCLOSURE STATEMENT}

The authors are not aware of any biases that might be perceived as affecting the objectivity of this review.

\section{ACKNOWLEDGMENTS}

We are grateful to The Rockefeller University Press, Elsevier, and The American Society of Plant Biologists for permission to reproduce parts of Figure 3 of this review. We thank Mitsuru Niihama and Miyo Terao Morita for providing high-quality figure files for the reproduction of published data. We acknowledge Nana Zappel for help in generating phylogenetic trees and Matt Humphry for proofreading. Work in the lab of V.L. is supported by the Deutsche Forschungsgemeinschaft and the Gatsby Charitable foundation. Work in the lab of R.P. is supported by grants from the Max-Planck Society and the Deutsche Forschungsgemeinschaft.

\section{LITERATURE CITED}

An QL, Hückelhoven R, Kogel KH, Van Bel AJE. 2006. Multivesicular bodies participate in a cell wall-associated defence response in barley leaves attacked by the pathogenic powdery mildew fungus. Cell Microbiol. 8:1009-19

Assaad FF, Huet Y, Mayer U, Jürgens G. 2001. The cytokinesis gene KEULE encodes a Sec1 protein that binds the syntaxin KNOLLE. F. Cell Biol. 152:531-43

Assaad FF, Qiu JL, Youngs H, Ehrhardt D, Zimmerli L, et al. 2004. The PEN1 syntaxin defines a novel cellular compartment upon fungal attack and is required for the timely assembly of papillae. Mol. Biol. Cell 15:5118-29

Bassham DC, Gal S, Conceicao AD, Raikhel NV. 1995. An Arabidopsis syntaxin homologue isolated by functional complementation of a yeast pep12 mutant. Proc. Natl. Acad. Sci. USA 92:7262-66

Bassham DC, Raikhel NV. 1998. An Arabidopsis VPS45p homolog implicated in protein transport to the vacuole. Plant Physiol. 117:407-15

Bassham DC, Raikhel NV. 1999. The pre-vacuolar t-SNARE AtPEP12p forms a 20S complex that dissociates in the presence of ATP. Plant F. 19:599-603

Bassham DC, Raikhel NV. 2000. Unique features of the plant vacuolar sorting machinery. Curr. Opin. Cell Biol. 12:491-95

Bassham DC, Sanderfoot AA, Kovaleva V, Zheng HY, Raikhel NV. 2000. AtVPS45 complex formation at the trans-Golgi network. Mol. Biol. Cell 11:2251-65 
Provided the first genetic evidence for a role of SNAREs in plant defense and documented a conserved role for a PM-resident syntaxin in antifungal resistance.
Baumert M, Maycox PR, Navone F, Decamilli P, Jahn R. 1989. Synaptobrevin: an integral membrane-protein of 18000 daltons present in small synaptic vesicles of rat-brain. EMBO 7. 8:379-84

Bennett MK, Calakos N, Scheller RH. 1992. Syntaxin: a synaptic protein implicated in docking of synaptic vesicles at presynaptic active zones. Science 257:255-59

Bhat RA, Miklis M, Schmelzer E, Schulze-Lefert P, Panstruga R. 2005. Recruitment and interaction dynamics of plant penetration resistance components in a plasma membrane microdomain. Proc. Natl. Acad. Sci. USA 102:3135-40

Bhat RA, Panstruga R. 2005. Lipid rafts in plants. Planta 223:5-19

Blancaflor EB, Masson PH. 2003. Plant gravitropism. Unraveling the ups and downs of a complex process. Plant Physiol. 133:1677-90

Bock JB, Matern HT, Peden AA, Scheller RH. 2001. A genomic perspective on membrane compartment organization. Nature 409:839-41

Brunger AT. 2006. Structure and function of SNARE and SNARE-interacting proteins. $Q$. Rev. Biophys. 38:1-47

Carr JP, Dixon DC, Nikolau BJ, Voelkerding KV, Klessig DF. 1987. Synthesis and localization of pathogenesis-related proteins in tobacco. Mol. Cell. Biol. 7:1580-83

Carter C, Pan SQ, Jan ZH, Avila EL, Girke T, Raikhel NV. 2004. The vegetative vacuole proteorne of Arabidopsis thaliana reveals predicted and unexpected proteins. Plant Cell 16:3285-303

Catalano CM, Czymmek KJ, Gann JG, Sherrier DJ. 2007. Medicago truncatula syntaxin SYP132 defines the symbiosome membrane and infection droplet membrane in root nodules. Planta 225:541-50

Catalano CM, Lane WS, Sherrier DJ. 2004. Biochemical characterization of symbiosome membrane proteins from Medicago truncatula root nodules. Electrophoresis 25:519-31

Chamberlain LH, Burgoyne RD, Gould GW. 2001. SNARE proteins are highly enriched in lipid rafts in PC12 cells: implications for the spatial control of exocytosis. Proc. Natl. Acad. Sci. USA 98:5619-24

Chatre L, Brandizzi F, Hocquellet A, Hawes C, Moreau P. 2005. Sec22 and Memb11 are $\mathrm{v}$-SNAREs of the anterograde endoplasmic reticulum-Golgi pathway in tobacco leaf epidermal cells. Plant Physiol. 139:1244-54

Chen Y, Shin YK, Bassham DC. 2005. YKT6 is a core constituent of membrane fusion machineries at the Arabidopsis trans-Golgi network. 7. Mol. Biol. 350:92-101

Collins NC, Thordal-Christensen H, Lipka V, Bau S, Kombrink E, et al. 2003. SNAREprotein-mediated disease resistance at the plant cell wall. Nature 425:973-77

Conceicao ADS, Marty-Mazars D, Bassham DC, Sanderfoot AA, Marty F, Raikhel NV. 1997. The syntaxin homolog AtPEP12p resides on a late post-Golgi compartment in plants. Plant Cell 9:571-82

Deneka M, Neeft M, van der Sluijs P. 2003. Regulation of membrane transport by rab GTPases. Crit. Rev. Biochem. Mol. Biol. 38:121-42

Dhonukshe P, Baluska F, Schlicht M, Hlavacka A, Samaj J, et al. 2006. Endocytosis of cell surface material mediates cell plate formation during plant cytokinesis. Dev. Cell 10:13750

Douchkov D, Nowara D, Zierold U, Schweizer P. 2005. A high-throughput gene-silencing system for the functional assessment of defense-related genes in barley epidermal cells. Mol. Plant-Microbe Interact. 18:755-61

Dulubova I, Sugita S, Hill S, Hosaka M, Fernandez I, et al. 1999. A conformational switch in syntaxin during exocytosis: role of munc18. EMBO F. 18:4372-82 
Eichmann R, Dechert C, Kogel KH, Hückelhoven R. 2006. Transient over-expression of barley BAX Inhibitor-1 weakens oxidative defence and MLA12-mediated resistance to Blumeria graminis f.sp hordei. Mol. Plant Pathol. 7:543-52

Elias M, Drdova E, Ziak D, Bavlnka B, Hala M, et al. 2003. The exocyst complex in plants. Cell Biol. Int. 27:199-201

Fasshauer D, Sutton RB, Brunger AT, Jahn R. 1998. Conserved structural features of the synaptic fusion complex: SNARE proteins reclassified as Q- and R-SNAREs. Proc. Natl. Acad. Sci. USA 95:15781-86

Fernandez I, Ubach J, Dulubova I, Zhang XY, Sudhof TC, Rizo J. 1998. Three-dimensional structure of an evolutionarily conserved N-terminal domain of syntaxin 1A. Cell 94:841-49

Foresti O, daSilva LLP, Denecke J. 2006. Overexpression of the Arabidopsis syntaxin PEP12/SYP21 inhibits transport from the prevacuolar compartment to the lytic vacuole in vivo. Plant Cell 18:2275-93

Fuchs U, Hause G, Schuchardt I, Steinberg G. 2006. Endocytosis is essential for pathogenic development in the corn smut fungus Ustilago maydis. Plant Cell 18:2066-81

Fukaki H, Fujisawa H, Tasaka M. 1996. SGR1, SGR2, and SGR3: novel genetic loci involved in shoot gravitropism in Arabidopsis thaliana. Plant Physiol. 110:945-55

Geelen D, Leyman B, Batoko H, Di Sansabastiano GP, Moore I, Blatt MR. 2002. The abscisic acid-related SNARE homolog NtSyr1 contributes to secretion and growth: evidence from competition with its cytosolic domain. Plant Cell 14:387-406

Gerst JE. 2003. SNARE regulators: matchmakers and matchbreakers. Biochim. Biophys. Acta 1641:99-110

Gómez-Gómez L, Boller T. 2002. Flagellin perception: a paradigm for innate immunity. Trends Plant Sci. 7:251-56

Gonzalo S, Greentree WK, Linder ME. 1999. SNAP-25 is targeted to the plasma membrane through a novel membrane-binding domain. 7. Biol. Chem. 274:21313-18

Hanton SL, Brandizzi F. 2006. Protein transport in the plant secretory pathway. Can. F. Bot. 84:523-30

Heese M, Gansel X, Sticher L, Wick P, Grebe M, et al. 2001. Functional characterization of the KNOLLE-interacting t-SNARE AtSNAP33 and its role in plant cytokinesis. F. Cell Biol. 155:239-49

Heese A, Ludwig AA, Jones JDG. 2005. Rapid phosphorylation of a syntaxin during the Avr9/Cf-9-race-specific signaling pathway. Plant Physiol. 138:2406-16

Hepler PK, Vidali L, Cheung AY. 2001. Polarized cell growth in higher plants. Annu. Rev. Cell Dev. Biol. 17:159-87

Hong W. 2005. SNAREs and traffic. Biochim. Biophys. Acta 1744:493-517

Hückelhoven R, Fodor J, Preis C, Kogel KH. 1999. Hypersensitive cell death and papilla formation in barley attacked by the powdery mildew fungus are associated with hydrogen peroxide but not with salicylic acid accumulation. Plant Physiol. 119:1251-60

International Rice Genome Sequencing Project. 2005. The map-based sequence of the rice genome. Nature 436:793-800

Jahn R, Scheller RH. 2006. SNAREs: engines for membrane fusion. Nat. Rev. Mol. Cell Biol. 7:631-43

Kargul J, Gansel X, Tyrrell M, Sticher L, Blatt MR. 2001. Protein-binding partners of the tobacco syntaxin NtSyr1. FEBS Lett. 508:253-58

Kato T, Morita MT, Fukaki H, Yamauchi Y, Uehara M, et al. 2002. SGR2, a phospholipase-like protein, and ZIG/SGR4, a SNARE, are involved in the shoot gravitropism of Arabidopsis. Plant Cell 14:33-46
Comprehensively reviews mechanistic details of SNARE complex formation and the role of SNARE proteins as engines for membrane fusion. 
The first to describe a long-sought-after phenotype (in abiotic stress responses) for loss-of-function alleles of $\mathbf{R}$ SNARE-encoding genes.

Provides the first
genetic evidence
(although it is
based on
antisense-mediated
gene silencing and
thus not fully
conclusive) for a
contribution of a
SNARE in
symbiosis (root
nodule formation).

Provides the first (although it is based on antisense-mediated gene silencing and thus not fully conclusive) for a contribution of a SNARE in nodule formation).
Koticha DK, Huddleston SJ, Witkin JW, Baldini G. 1999. Role of the cysteine-rich domain of the t-SNARE component, SYNDET, in membrane binding and subcellular localization. 7. Biol. Chem. 274:9053-60

Lang T, Bruns D, Wenzel D, Riedel D, Holroyd P, et al. 2001. SNAREs are concentrated in cholesterol-dependent clusters that define docking and fusion sites for exocytosis. EMBO 7. 20:2202-13

Latijnhouwers M, Hawes C, Carvalho C, Oparka K, Gillingham AK, Boevink P. 2005. An Arabidopsis GRIP domain protein locates to the trans-Golgi and binds the small GTPase ARL1. Plant 7. 44:459-70

Lauber MH, Waizenegger I, Steinmann T, Schwarz H, Mayer U, et al. 1997. The Arabidopsis KNOLLE protein is a cytokinesis-specific syntaxin. F. Cell Biol. 139:1485-93

Lerman JC, Robblee J, Fairman R, Hughson FM. 2000. Structural analysis of the neuronal SNARE protein syntaxin-1A. Biochemistry 39:8470-79

Leshem Y, Melamed-Book N, Cagnac O, Ronen G, Nishri Y, et al. 2006. Suppression of Arabidopsis vesicle-SNARE expression inhibited fusion of $\mathrm{H}_{2} \mathrm{O}_{2}$ containing vesicles with tonoplast and increased salt tolerance. Proc. Natl. Acad. Sci. USA 103:18008-13

Levine A, Belenghi B, Damari-Weisler H, Granot D. 2001. Vesicle-associated membrane protein of Arabidopsis suppresses Bax-induced apoptosis in yeast downstream of oxidative burst. F. Biol. Chem. 276:46284-89

Leyman B, Geelen D, Blatt MR. 2000. Localization and control of expression of Nt-Syr1, a tobacco snare protein. Plant F. 24:369-81

Leyman B, Geelen D, Quintero FJ, Blatt MR. 1999. A tobacco syntaxin with a role in hormonal control of guard cell ion channels. Science 283:537-40

Lipka V, Panstruga R. 2005. Dynamic cellular responses in plant-microbe interactions. Curr. Opin. Plant Biol. 8:625-31

Lukowitz W, Mayer U, Jürgens G. 1996. Cytokinesis in the Arabidopsis embryo involves the syntaxin-related KNOLLE gene product. Cell 84:61-71

Mai HT, Nomura M, Takegawa K, Asamizu E, Sato S, et al. 2006. Identification of a Sed5-like SNARE gene LjSYP32-1 that contributes to nodule tissue formation of Lotus japonicus. Plant Cell Physiol. 47:829-38

Mao CH, Qiu J, Wang CX, Charles TC, Sobral BWS. 2005. NodMutDB: a database for genes and mutants involved in symbiosis. Bioinformatics 21:2927-29

Marmagne A, Rouet MA, Ferro M, Rolland N, Alcon C, et al. 2004. Identification of new intrinsic proteins in Arabidopsis plasma membrane proteome. Mol. Cell. Proteomics 3:67591

Martinez-Arca S, Rudge R, Vacca M, Raposo G, Camonis J, et al. 2003. A dual mechanism controlling the localization and function of exocytic v-SNAREs. Proc. Natl. Acad. Sci. USA 100:9011-16

Masson PH, Tasaka M, Morita MT, Guan C, Chen R, Boonsirichai K. 2002. Arabidopsis thaliana: a model system for the study of root and shoot gravitropism. In The Arabidopsis Book, ed. CR Somerville, EM Meyerowitz. Rockville, MD: Am. Soc. Plant Biol. doi: 10.1199/tab.0009; available at http://www.aspb.org/publications/arabidopsis/

May AP, Whiteheart SW, Weis WI. 2001. Unraveling the mechanism of the vesicle transport ATPase NSF, the $N$-ethylmaleimide sensitive factor. F. Biol. Chem. 276:21991-94

Mayer U, Jürgens G. 2004. Cytokinesis: lines of division taking shape. Curr. Opin. Plant Biol. 7:599-604

McNew JA, Sogaard M, Lampen NM, Machida S, Ye RR, et al. 1997. Ykt6p, a prenylated SNARE essential for endoplasmic reticulum golgi transport. F. Biol. Chem. 272:17776-83 
Misura KMS, Scheller RH, Weis WI. 2000. Three-dimensional structure of the neuronalSec1/syntaxin complex. Nature 404:355-62

Mongrand S, Morel J, Laroche J, Claverol S, Carde JP, et al. 2004. Lipid rafts in higher plant cells: purification and characterization of triton X-100-insoluble microdomains from tobacco plasma membrane. 7. Biol. Chem. 279:36277-86

Morel J, Claverol S, Mongrand S, Furt F, Fromentin J, et al. 2006. Proteomics of plant detergent-resistant membranes. Mol. Cell. Proteomics 5:1396-411

Morita MT, Kato T, Nagafusa K, Saito C, Ueda T, et al. 2002. Involvement of the vacuoles of the endodermis in the early process of shoot gravitropism in Arabidopsis. Plant Cell $14: 47-56$

Müller I, Wagner W, Volker A, Schellmann S, Nacry P, et al. 2003. Syntaxin specificity of cytokinesis in Arabidopsis. Nat. Cell Biol. 5:531-34

Munson M, Chen X, Cocina AE, Schultz SM, Hughson FM. 2000. Interactions within the yeast t-SNARE Sso1p that control SNARE complex assembly. Nat. Struct. Biol. 7:894-902

Naren AP, Nelson DJ, Xie WW, Jovov B, Pevsner J, et al. 1997. Regulation of CFTR chloride channels by syntaxin and Munc18 isoforms. Nature 390:302-5

Nebenführ A, Frohlick JA, Staehelin LA. 2000. Redistribution of Golgi stacks and other organelles during mitosis and cytokinesis in plant cells. Plant Physiol. 124:135-51

Niihama M, Uemura T, Saito C, Nakano A, Sato MH, et al. 2005. Conversion of functional specificity in Qb-SNARE VTI1 homologues of Arabidopsis. Curr. Biol. 15:555-60

Nühse TS, Boller T, Peck SC. 2003. A plasma membrane syntaxin is phosphorylated in response to the bacterial elicitor flagellin. F. Biol. Chem. 278:45248-54

Ohtomo I, Ueda H, Shimada T, Nishiyama C, Komoto Y, et al. 2005. Identification of an allele of VAM3/SYP22 that confers a semi-dwarf phenotype in Arabidopsis thaliana. Plant Cell Physiol. 46:1358-65

Pike LJ. 2006. Rafts defined: a report on the Keystone Symposium on Lipid Rafts and Cell Function. 7. Lipid Res. 47:1597-98

Pratelli J, Sutter JU, Blatt MR. 2004. A new catch in the SNARE. Trends Plant Sci. 9:187-95

Rancour DM, Dickey CE, Park S, Bednarek SY. 2002. Characterization of AtCDC48. Evidence for multiple membrane fusion mechanisms at the plane of cell division in plants. Plant Physiol. 130:1241-53

Robatzek S, Chinchilla D, Boller T. 2006. Ligand-induced endocytosis of the pattern recognition receptor FLS2 in Arabidopsis. Genes Dev. 20:537-42

Rojo E, Gillmor CS, Kovaleva V, Somerville CR, Raikhel NV. 2001. VACUOLELESS1 is an essential gene required for vacuole formation and morphogenesis in Arabidopsis. Dev. Cell $1: 303-10$

Sack FD. 1991. Plant gravity sensing. Int. Rev. Cytol. 127:193-252

Saito C, Morita MT, Kato T, Tasaka M. 2005. Amyloplasts and vacuolar membrane dynamics in the living graviperceptive cell of the Arabidopsis inflorescence stem. Plant Cell 17:548-58

Salaün C, James DJ, Chamberlain LH. 2004. Lipid rafts and the regulation of exocytosis. Traffic 5:255-64

Samuels AL, Giddings TH, Staehelin LA. 1995. Cytokinesis in tobacco BY-2 and root tip cells: a new model of cell plate formation in higher plants. F. Cell Biol. 130:1345-57

Sanderfoot AA, Assaad FF, Raikhel NV. 2000. The Arabidopsis genome. An abundance of soluble $N$-ethylmaleimide-sensitive factor adaptor protein receptors. Plant Physiol. 124:155869
An elegant demonstration that multiple parameters (timing of gene expression, subcellular localization, and intrinsic features of the polypeptide) contribute to specificity of in planta SNARE function.

Nicely illustrates how a single amino acid substitution can convert specificity of an individual SNARE in SNARE-complex formation. 
Sanderfoot AA, Kovaleva V, Bassham DC, Raikhel NV. 2001a. Interactions between syntaxins identify at least five SNARE complexes within the Golgi/prevacuolar system of the Arabidopsis cell. Mol. Biol. Cell 12:3733-43

Sanderfoot AA, Pilgrim M, Adam L, Raikhel NV. 2001b. Disruption of individual members of Arabidopsis syntaxin gene families indicates each has essential functions. Plant Cell 13:65966

Sanderfoot AA, Raikhel N. 2003. The secretory system of Arabidopsis. In The Arabidopsis Book, ed. CR Somerville, EM Meyerowitz. Rockville, MD: Am. Soc. Plant Biol. doi: 10.1199/tab.0009; available at http://www.aspb.org/publications/arabidopsis/

Sato MH, Nakamura N, Ohsumi Y, Kouchi H, Kondo M, et al. 1997. The AtVAM3 encodes a syntaxin-related molecule implicated in the vacuolar assembly in Arabidopsis thaliana. 7 . Biol. Chem. 272:24530-35

Schulze-Lefert P. 2004. Knocking on heaven's wall: pathogenesis of and resistance to biotrophic fungi at the cell wall. Curr. Opin. Plant Biol. 7:377-83

Seguí-Simarro JM, Austin JR, White EA, Staehelin LA. 2004. Electron tomographic analysis of somatic cell plate formation in meristematic cells of Arabidopsis preserved by high-pressure freezing. Plant Cell 16:836-56

Shimada C, Lipka V, O'Connel R, Okuno T, Schulze-Lefert P, Takano Y. 2006. Nonhost resistance in Arabidopsis-Colletotrichum interactions acts at the cell periphery and requires actin filament function. Mol. Plant-Microbe Interact. 19:270-79

Snyder BA, Nicholson RL. 1990. Synthesis of phytoalexins in Sorghum as a site-specific response to fungal ingress. Science 248:1637-39

Sohn EJ, Kim ES, Zhao M, Kim SJ, Kim H, et al. 2003. Rha1, an Arabidopsis Rab5 homolog, plays a critical role in the vacuolar trafficking of soluble cargo proteins. Plant Cell 15:105770

Söllner R, Glasser G, Wanner G, Somerville CR, Jürgens G, Assaad FF. 2002. Cytokinesisdefective mutants of Arabidopsis. Plant Physiol. 129:678-90

Söllner T, Whitehart SW, Brunner M, Erdjumentbromage H, Geromanos S, et al. 1993. SNAP receptors implicated in vesicle targeting and fusion. Nature 362:318-24

Surpin M, Raikhel N. 2004. Traffic jams affect plant development and signal transduction. Nat. Rev. Mol. Cell Biol. 5:100-9

Surpin M, Zheng HJ, Morita MT, Saito C, Avila E, et al. 2003. The VTI family of SNARE proteins is necessary for plant viability and mediates different protein transport pathways. Plant Cell 15:2885-99

Sutter JU, Campanoni P, Blatt MR, Paneque M. 2006a. Setting SNAREs in a different wood. Traffic 7:627-38

Sutter JU, Campanoni P, Tyrrell M, Blatt MR. 2006b. Selective mobility and sensitivity to SNAREs is exhibited by the Arabidopsis KAT1 $\mathrm{K}^{+}$channel at the plasma membrane. Plant Cell 18:935-54

Tai WCS, Banfield DK. 2001. AtBS14a and AtBS14b, two Bet1/Sft1-like SNAREs from Arabidopsis thaliana that complement mutations in the yeast SFT1 gene. FEBS Lett. 500:17782

Takeuchi M, Ueda T, Yahara N, Nakano A. 2002. Arf1 GTPase plays roles in the protein traffic between the endoplasmic reticulum and the Golgi apparatus in tobacco and Arabidopsis cultured cells. Plant 7. 31:499-515

The Arabidopsis Genome Initiative. 2000. Analysis of the genome sequence of the flowering plant Arabidopsis thaliana. Nature 408:796-815

Tuskan GA, DiFazio S, Jansson S, Bohlmann J, Grigoriev I, et al. 2006. The genome of black cottonwood, Populus trichocarpa (Torr. \& Gray). Science 313:1596-604 
Ueda H, Nishiyama C, Shimada T, Koumoto Y, Hayashi Y, et al. 2006. AtVAM3 is required for normal specification of idioblasts, myrosin cells. Plant Cell Physiol. 47:164-75

Uemura T, Sato MH, Takeyasu K. 2005. The longin domain regulates subcellular targeting of VAMP7 in Arabidopsis thaliana. FEBS Lett. 579:2842-46

Uemura T, Ueda T, Ohniwa RL, Nakano A, Takeyasu K, Sato MH. 2004. Systematic analysis of SNARE molecules in Arabidopsis: dissection of the post-Golgi network in plant cells. Cell Struct. Funct. 29:49-65

Varlamov O, Volchuk A, Rahimian V, Doege CA, Paumet F, et al. 2004. i-SNAREs: inhibitory SNAREs that fine-tune the specificity of membrane fusion. 7. Cell Biol. 164:79-88

Veit M, Söllner TH, Rothman JE. 1996. Multiple palmitoylation of synaptotagmin and the t-SNARE SNAP-25. FEBS Lett. 385:119-23

Völker A, Stierhof YD, Jürgens G. 2001. Cell cycle-independent expression of the Arabidopsis cytokinesis-specific syntaxin KNOLLE results in mistargeting to the plasma membrane and is not sufficient for cytokinesis. F. Cell Sci. 114:3001-12

Waizenegger I, Lukowitz W, Assaad F, Schwarz H, Jürgens G, Mayer U. 2000. The Arabidopsis $K N O L L E$ and KEULE genes interact to promote vesicle fusion during cytokinesis. Curr. Biol. 10:1371-74

Wick P, Gansel X, Oulevey C, Page V, Studer I, et al. 2003. The expression of the t-SNARE AtSNAP33 is induced by pathogens and mechanical stimulation. Plant Physiol. 132:343-51

Yamauchi Y, Fukaki H, Fujisawa H, Tasaka M. 1997. Mutations in the SGR4, SGR5 and SGR6 loci of Arabidopsis thaliana alter the shoot gravitropism. Plant Cell Physiol. 38:530-35

Yang B, Steegmaier M, Gonzalez LJ, Scheller RH. 2000. nSec1 binds a closed conformation of syntaxin1A. F. Cell Biol. 148:247-52

Yano D, Sato M, Saito C, Sato MH, Morita MT, Tasaka M. 2003. A SNARE complex containing SGR3/AtVAM3 and ZIG/VTI11 in gravity-sensing cells is important for Arabidopsis shoot gravitropism. Proc. Natl. Acad. Sci. USA 100:8589-94

Zhang Z, Feechan A, Pedersen C, Newman MA, Qiu J, et al. 2007. A SNARE protein has opposing functions in penetration resistance and defence signalling pathways. Plant $\mathcal{F}$. 49:302-12

Zheng H, Camacho L, Wee E, Batoko H, Legen J, et al. 2005. A Rab-E GTPase mutant acts downstream of the Rab-D subclass in biosynthetic membrane traffic to the plasma membrane in tobacco leaf epidermis. Plant Cell 17:2020-36

Zheng HY, Bassham DC, Conceicao AD, Raikhel NV. 1999a. The syntaxin family of proteins in Arabidopsis: a new syntaxin homologue shows polymorphism between two ecotypes. $\mathcal{F}$. Exp. Bot. 50:915-24

Zheng HY, Bednarek SY, Sanderfoot AA, Alonso J, Ecker JR, Raikhel NV. 2002. NPSN11 is a cell plate-associated SNARE protein that interacts with the syntaxin KNOLLE. Plant Physiol. 129:530-39

Zheng HY, von Mollard GF, Kovaleva V, Stevens TH, Raikhel NV. 1999b. The plant vesicleassociated SNARE AtVTI1a likely mediates vesicle transport from the trans-Golgi network to the prevacuolar compartment. Mol. Biol. Cell 10:2251-64

Zhu JH, Gong ZZ, Zhang CQ, Song CP, Damsz B, et al. 2002. OSM1/SYP61: a syntaxin protein in Arabidopsis controls abscisic acid-mediated and non-abscisic acidmediated responses to abiotic stress. Plant Cell 14:3009-28

Zimmermann P, Hirsch-Hoffmann M, Hennig L, Gruissem W. 2004. GENEVESTIGATOR. Arabidopsis microarray database and analysis toolbox. Plant Physiol. 136:2621-32

Zipfel C, Robatzek S, Navarro L, Oakeley EJ, Jones JDG, et al. 2004. Bacterial disease resistance in Arabidopsis through flagellin perception. Nature 428:764-67
Provides the first firm genetic evidence (based on a loss-of-function mutant allele) for the contribution of a SNARE in plant abiotic stress responses. 


\section{RELATED RESOURCES}

Plant SNAREs. Genomic analysis of Arabidopsis, rice, and Chlamydomonas SNAREs: http://www.cbs.umn.edu/ sande099/pln_snare.htm

Arabidopsis SNAREs. Genomic analysis of SNAREs: http://www.cbs.umn.edu/ sande099/ atsnare.htm 